DIW BERLIN

Discussion

Papers
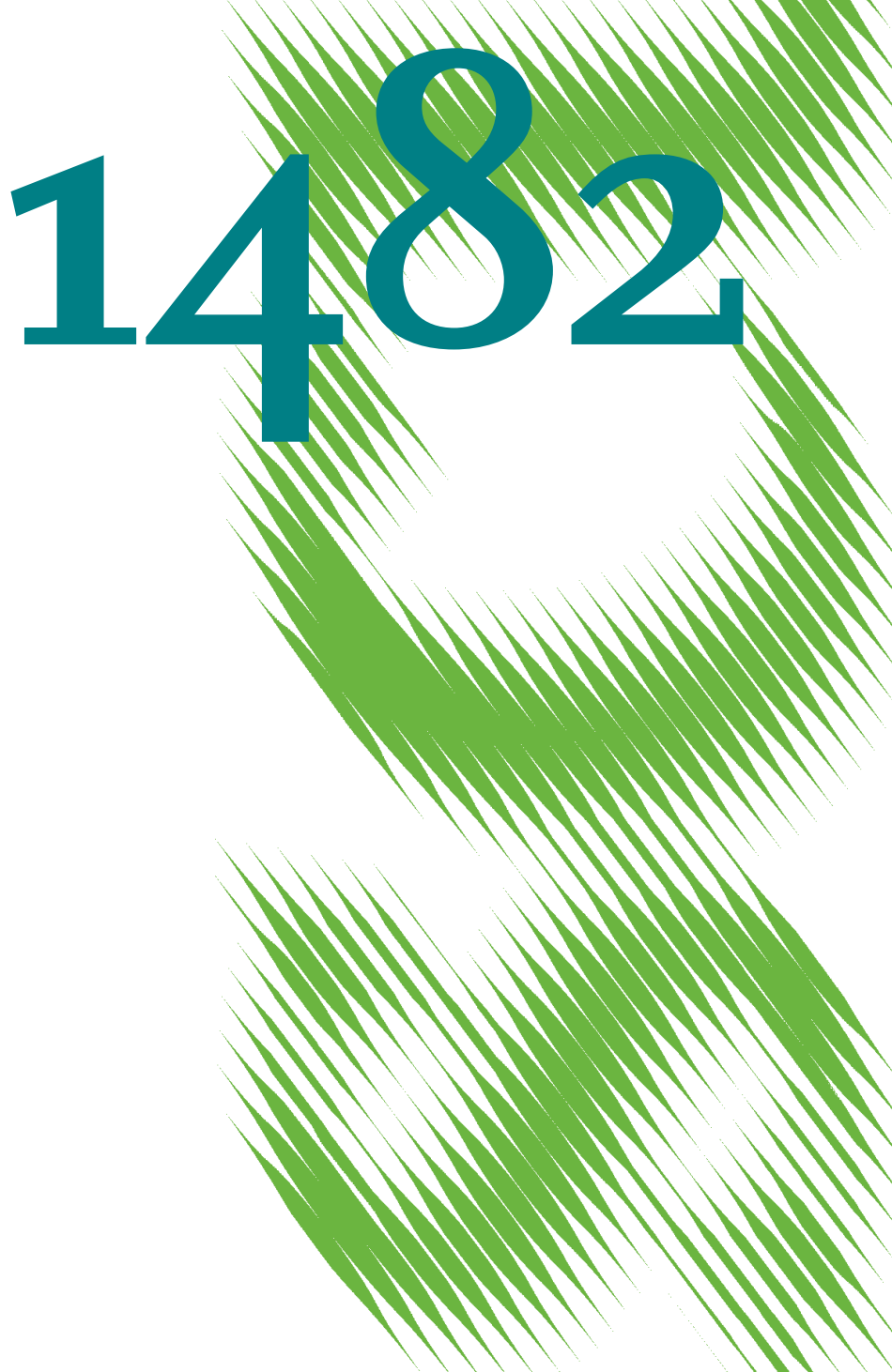

European-Wide Inequality in Times of the Financial Crisis 
Opinions expressed in this paper are those of the author(s) and do not necessarily reflect views of the institute.

IMPRESSUM

(C) DIW Berlin, 2015

DIW Berlin

German Institute for Economic Research

Mohrenstr. 58

10117 Berlin

Tel. +49 (30) $89789-0$

Fax +49 (30) $89789-200$

http://www.diw.de

ISSN electronic edition 1619-4535

Papers can be downloaded free of charge from the DIW Berlin website:

http://www.diw.de/discussionpapers

Discussion Papers of DIW Berlin are indexed in RePEc and SSRN:

http://ideas.repec.org/s/diw/diwwpp.html

http://www.ssrn.com/link/DIW-Berlin-German-Inst-Econ-Res.html 


\title{
European-Wide Inequality in Times of the Financial Crisis ${ }^{+}$
}

\author{
Timm Bönke* and Carsten Schröder ${ }^{* *}$
}

April 2015

\begin{abstract}
In view of rising concerns over increasing inequality in the European Union since the financial crisis, this study provides an inequality decomposition of the overall European income distribution by country. The EU Statistics on Income and Living Conditions are our empirical basis. Inequality has risen moderately within the core Euro area, particularly in the last two years of the observation period (2010/11). Widening disparities between EU Member States are the driving force behind this trend, while inequalities within countries do not exhibit systematic changes. An analysis of binational distributions reveals that it is the countries hit worst by the crisis-Greece and Spain-for which the between-country disparities have changed most markedly.
\end{abstract}

Keywords: Inequality, decomposition, crisis

JEL codes: D30, D31, D39

\footnotetext{
+ We thank Charlotte Bartels, Markus Grabka, Johannes König, Holger Lüthen, and Jürgen Schupp for valuable comments. The usual disclaimer applies.

*School of Business \& Economics, Freie Universität Berlin, timm.boenke@fu-berlin.de

** DIW Berlin / SOEP and School of Business \& Economics, Freie Universität Berlin, cschroeder@diw.de
} 


\section{Introduction}

The financial crisis of $2007 / 8$ was followed by a substantial contraction in the global economy: the "Great Recession." Not only has this recession lowered the average living standard, it has probably also changed personal income and wealth distributions. Recent evidence for the US suggests that in recessions, the income of the middle class declines steadily and moderately, while that of both the poor and the rich declines steeply and abruptly (Guvenen et al., 2014). Further, recessions are often accompanied by a misallocation of resources in the economy. Presumably, the economically weak suffer most from the income loss (including cuts in social programs) and misallocation of funds. If prices of assets drop drastically, the wealth of different groups of asset holders and the related returns change drastically as well. This phenomenon of "excess volatility of assets" follows the business and credit cycle. The financial crisis preceding the Great Recession hence implies a bust for both of these cycles, with all the distributional consequences that entails.

The vast majority of studies investigate the distributive effects of the financial crisis and the Great Recession at the national level. For example, Georgopoulos et al. (2012) show that the countries hit worst by the crisis had the highest inequality indices before the crisis. A comprehensive analysis of the impact on the Great Recession on several country-level income distributions is provided by Jenkins et al. (2013). Other national-level analyses include Avram et al. (2013) Roine et al. (2009), Dagdeviren (2014), Hellebrandt (2014), De Beer (2012), Theodoropoulo and Watt (2011), and Grabka (2015). To our knowledge, only Dauderstädt and Keltek (2012) have estimated EU-wide inequality in the first years of the crisis.

Focusing on the nation as the unit of analysis seems especially inappropriate in the context of the EU, with its far-reaching economic, financial and political mutual commitments: convergence in living standards between Member States and abatement of social deprivation within them are central goals of EU policies. Among the $28 \mathrm{EU}$ Member States, the common market guarantees free mobility of goods, services, capital and labor, and many policy areas are harmonized. In a subset of 18 Member States, the euro zone, a single monetary policy has been adopted. Disparities between countries are the focus of EU regional policies (see TFEU Art. 174-178). The Open Method of Coordination serves as a framework for coordinating national social policies, and the European Social Fund promotes employment opportunities. For Pogge and Reddy (2002) and Singer (2002), inequalities in such a supra-national entity are also an ethical issue.

Against this backdrop, the question arises how disparities in material living standards in the EU as a whole have changed during the crisis period. A key macro indicator of material living standard in a society is gross domestic product (GDP). This indicator showed substantial disparities in average living standard even before the crisis. For example, in 2007, average per capita GDP in the European Union was about 27,458 EUR. Per capita GDP in Luxembourg was about 3.1 times the EU average, while it was only 0.40 times the average in Hungary, 
and 0.64 times in Poland. ${ }^{1}$ Figure 1 gives GDP growth rates for selected EU countries for the period 2004-11. As can be seen, the financial crisis caused substantial reductions in GDP per capita, with some countries (e.g., Portugal and Spain) being hit harder than others (e.g., Luxembourg and Germany). By 2012, EU-wide GDP (26,650 EUR) had recovered to 2008 levels. During this recovery, the relative disparities widened. Currently, GDP per capita in Luxembourg is about 3.25 times the EU average, 0.38 times in Hungary, and 0.61 times in Poland.

\section{Figure 1 about here}

These numbers illustrate that the crisis changed not only the distributions but also the living standard differentials between countries. Combining the two sources provides insights into the evolution of inequality in an increasingly interconnected region. Motivated by the rising concern about widening disparities in living standards in the EU, this study provides an inequality decomposition of the Europe-wide distribution of living standards by country. The results are potentially of interest not only to the research community but also to supranational policy makers, because the higher the EU-wide disparities in living standards, "the more fragile is the process of European integration" (Brandolini, 2007: 20). ${ }^{2}$

Our living standard indicator is needs-adjusted (equivalent) disposable household income adjusted by purchasing power parities (PPP): PPP-EI. Household micro data from the EU Statistics on Income and Living Conditions (EU-SILC) serve as our empirical basis. Particularly, we provide two types of analysis. First, we study the EU-wide distribution of living standards around the financial crises, i.e., from 2004 to 2011. The EU-wide PPP-El distribution is constructed by assigning a household's PPP-El to every household member and using population weights from EU-SILC to inflate to the country-specific population sizes. We split inequality within the EU into two basic components: inequality within countries and inequality between countries. We perform the analysis for two sets of countries: a) the 2001 Euro currency area except for Belgium and Ireland (EA-10); b) and a wider set of 22 EU countries (EU-22). Second, on a more disaggregated level, we provide inequality estimates from binational distributions to assess how disparities in living standards have evolved between "neighboring" countries. ${ }^{3}$

Between 2004 and 2011, inequality in the EA-10-wide distribution has increased moderately. This is true for both of the inequality indices used in the present study, the Theil and the Gini

\footnotetext{
${ }^{1}$ Own calculations based on World Bank Data online, accessed on December 27, 2014.

${ }^{2}$ See also Kuznets (1965).

${ }^{3}$ The decomposition approach also permits an assessment of how changes in country-specific population sizes change the distribution. However, the country-specific population shares in the overall EU population have changed only little during the observation period (see Table A1 in the Appendix). For this reason we have refrained from providing results from a separate analysis.
} 
index. The increase in inequality in the EA-10 in 2010 and 2011 is particularly striking. In the EU-22, the indices indicate a slight decrease of inequality before the crisis, and stagnating inequality afterwards. Widening disparities across Member States is the driving force behind the rise of inequality within the EA-10, and not rising inequalities within countries. This can be seen from the Theil-between (Gini-between) component. Its share in the overall index increases from 6.6 percent (20.6 percent) in 2004 to 12.2 percent (30.3) in 2011. The results for the EU-22 are different: Between 2004 and 2008, the between component of the indices decreases and remains relatively constant thereafter. Apparently, declining average living standards in the countries most severely hit by the financial crisis, i.e., Greece and Spain, towards the levels of the low-income EU-22 Member States have lowered inequalities between these countries.

Differences in average living standards across countries remain unobserved in country-level analyses. Increasing differences over time, captured by rising between-inequality components, however, are a key driver of rising inequalities within the EA-10. The analysis of the binational distributions reveals that it is the crisis countries Greece and Spain for which the between component has increased most markedly.

The following is an outline of our paper: Section 2 introduces the database. Section 3 deals with methodological issues, i.e., the inequality decomposition framework and bootstrapping. Section 4 summarizes the empirical findings of the EU-wide and binational inequality decomposition. Section 5 concludes the paper.

\section{Data}

\subsection{Data and types of countries}

Our analysis is based on the EU Statistics on Income and Living Conditions, EU-SILC. EU-SILC is coordinated by Eurostat and conducted by statistical institutions in the participating countries. The countries decide on the mode of collection of previously defined variables (cf. lacovou et al. 2012: 1; and: http://ec.europa.eu/eurostat/web/income-and-livingconditions/data). EU-SILC offers one of the most thorough cross-country micro datasets for income analysis in the EU. The ex-ante harmonization ensures comparability of data across countries. EU-SILC includes a variety of variables on income, labor, education, and other social indicators, based on surveys of private households in the EU Member States and a number of neighboring countries. Imputation in the case of item-non-response and weighting of the data to extrapolate the sample results to the total population of the countries are done following harmonized guidelines. EU-SILC is released in personal and household formats, and all income variables are provided in euros by year. ${ }^{4}$

\footnotetext{
${ }^{4}$ EU-SILC was implemented to provide harmonized data on living conditions across the EU Member States. For details on data quality and comparability see Lohmann (2011), Goedemé (2013), and Eurostat (2010).
} 
Our analysis is based on the most recently revised EU-SILC dataset, focusing on waves 2005 to 2012. We distinguish between two basic sets of EU countries following the European abbreviation structure (Eurostat 2014):

1. EA-12 - euro currency area in 2001;

2. EU-25 - EU Member States that entered the European Union by 2006.

For some countries (Belgium, Ireland, Malta), surveys are available only for selected waves (see Table 1). We have left these countries out of our study of EU-wide inequalities in order to obtain comparable statistics. This leaves us with the following sets of Member States:

1. $E A-10-A T, D E, E S, F I, F R, G R, I T, L U, N L, P T$;

2. EU-22 - AT, CY, CZ, DE, DK, EE, ES, FI, FR, GR, HU, IT, LT, LU, LV, NL, PL, PT, SE, SI, SK, UK.

In 2011, the last year of our period of analysis, the EA-10 had about $305,000,000$ inhabitants, the EU-22 had about 444,000,000. To ensure that our analysis remains in limits, we focus our analysis of the binational distributions on the set of EA-10 countries.

\section{Table 1 about here}

\subsection{Income concept}

Disposable household income is the basic measure for our empirical analysis. It is the sum of all individual and household-level income components (incl. social benefits and interhousehold cash transfer) minus taxes on income and social insurance contributions. Notice that in EU-SILC, incomes are provided in retrospect for the previous year. In the subsequent presentation, we have adjusted for this one-year lag, meaning that we report the statistics from the EU-SILC wave of year $X$ in year $X-1$.

Because we are interested in the distribution of material living standards, we make two adjustments to the raw household income data. To adjust for different price levels across countries, we consider purchasing power parities (PPP) from Eurostat (2014), summarized in Table A2 in the Appendix. To adjust for differences in needs across household types, we deflate the incomes with the OECD modified equivalence scale. The resulting income is PPPadjusted equivalent income (PPP-EI). ${ }^{5}$

We have discarded observations with non-positive and missing incomes. Furthermore, to avoid bias from outliers, we have winsorized the data: for every observation period and Member State, we replace observations with a disposable household income below (above)

\footnotetext{
${ }^{5}$ The OECD modified equivalence scale assigns a value of 1 to the household head, of 0.5 to each additional adult member and 0.3 to each child (household members below age 14).
} 
the first $\left(99^{\text {th }}\right)$ percentile by the upper (lower) threshold of the first $\left(99^{\text {th }}\right)$ percentile. All our basic results also hold for the data before winsorizing.

Figures $2 \mathrm{a}$ and $2 \mathrm{~b}$ provide Member State and period-specific descriptive statistics (arithmetic means together with the values from the $10^{\text {th }}, 50^{\text {th }}$ and $90^{\text {th }}$ percentile) on PPP-adjusted household income before equalization with the equivalence scale. As in all subsequent figures and tables, the product of EU-SILC frequency weights and the number of household members serve as weighting factors.

\section{Figures $2 \mathrm{a}$ and $\mathbf{2 b}$ about here}

Figure 3 provides kernel density estimates of PPP-EI in the EA-10 and EU-22 for the first and last year of our observation period (2004 and 2011) on a log scale. The four kernel densities suggest that PPP-EI within the EA-10 and EU-22 is approximately lognormally distributed. The EA-10 kernel density for 2011 is slightly more fanned out than the 2004 density, suggesting that PPP-El has become more unequally distributed since the financial crisis. For the EU-22, the densities of the 2004 and 2011 distributions hardly differ, suggesting that the overall distribution has remained rather stable.

\section{Figure 3 about here}

Next we turn to the country-specific densities of PPP-El. Figure 4a provides 10 graphs, one graph per EA-10 country. Figure $4 \mathrm{~b}$ provides the densities for the remaining twelve EU-22 countries. In each graph, four kernel density estimates are provided: the black solid (dashed) curve describes the density for the particular country in 2004 (2011), the grey solid and dashed curves refer to the EU-22 wide distribution. The first impression from the densities is that the EU-wide distribution is much more broadly dispersed than the country-specific distributions. This is particularly true for the EA-10 countries (except for Spain and Greece), but also for several EU-22 countries such as the Czech Republic, Sweden, and Denmark. The second impression is that the distributions of material living standards and the average thereof did not change much between 2004 and 2011. For Luxembourg and Spain and particularly for Greece, the kernel densities shift over time to the left, suggesting that average PPP-El has decreased over time. In contrast, PPP-El densities of most of the non-EA10 countries suggest a marked increase in average PPP-EI. This is particularly true for the Baltic countries, Poland, and Slovakia. The only exception in the non-EA-10 group of countries is the UK, where PPP-El decreased between 2004 and 2011. 


\section{Methods}

This section briefly summarizes the framework of our inequality analysis and describes how we decompose inequality and perform statistical inference on inequality indices.

We depict inequality in PPP-El distributions as if the European Union were a single country. Therefore, all incomes are weighted by household weighting factors times the number of household members, extrapolating the statistics to the total population of each Member State. ${ }^{6}$ To understand the mechanics underlying the evolution of EU-wide inequality in living standards, we perform an inequality decomposition by country. The basic idea of the decomposition is to express overall inequality as a function of inequality within and between countries, indexed by $k=1, \ldots, K$.

Decomposability of an inequality index implies that the index can be written as a weighted sum of two components. The within component is the weighted sum of the within-country inequality indices. The between component reflects inter-country differences in average living standards. Inequality indices of the generalized-entropy family, $G E(\theta)$, (mean log deviation: $G E(0)$, Theil index: $G E(1)$, half the square of coefficient of variation: $G E(2))$ are decomposable, and can be written as,

$$
G E(\theta)=G E W(\theta)+G E B(\theta),
$$

where $\operatorname{GEW}(\theta)$ is the within and $G E B(\theta)$ the between component. The within component is defined as,

$$
\begin{gathered}
G E W(\theta)=\sum_{k=1}^{K} q_{k} \times\left(\frac{\mu_{k}}{\mu}\right)^{\theta} \times G E_{k}(\theta), \quad \theta \neq 0 \\
G E W(0)=\sum_{k=1}^{K} q_{k} \times G E_{k}(0)
\end{gathered}
$$

The term $\mu$ denotes the mean of PPP-adjusted equivalent income in the EU, and $\mu_{k}$ the corresponding mean in Member State $k$. The term $q_{k}$ denotes the fraction of the overall EU population resident in $k$.

Between inequality is defined as,

\footnotetext{
${ }^{6}$ For the role of alternative weighting schemes for inequality comparisons, see Schröder and Bönke (2012) and references therein.
} 


$$
\begin{gathered}
G E B(\theta)=\frac{1}{\theta \times(\theta-1)} \sum_{k=1}^{K} q_{k}\left[\left(\frac{\mu_{k}}{\mu}\right)^{\theta}-1\right], \theta \neq 0,1 \\
G E B(\theta)=\sum_{k=1}^{K} q_{k} \times \ln \left(\frac{\mu}{\mu_{k}}\right), \theta=0,1 .
\end{gathered}
$$

In addition to the generalized entropy indices, we provide a decomposition exercise for the Gini index, GI. The Gini index is not decomposable into a within and between component, but a residual, $G I O$, remains. This residual captures the overlap of the country-specific income distributions. More precisely,

$$
G I=G I W+G I B+G I O
$$

The Gini within is defined as GIW $=\sum_{k=1}^{K} G I_{k} \times q_{k} \times s_{k}$, with $s_{k}$ denoting Member State $k^{\prime}$ s share of total EU-wide income (equivalent and PPP adjusted). Similar to the generalizedentropy class, the Gini within is the weighted sum of the country-specific Gini indices. The Gini between is $G I B=\sum_{k=1}^{K} \sum_{j>k}^{K}\left(\frac{\mu_{j}-\mu_{k}}{\mu_{k}}\right) \times q_{k} \times s_{j}$. It is the weighted sum of relative differences in mean equivalent PPP-adjusted incomes of any two countries.

To test for statistical significance of changes in inequality over time or differences across countries, we implement a bootstrap procedure following Biewen (2002). In a first step, we create a pooled dataset over all EA-10 (EU-22) countries. From the pooled database, we draw, with replacement, $B=1,000$ bootstrap samples, using countries as strata. Hereby, each Member State's bootstrap sample has as many sampling units (households) as the underlying country-specific EU-SILC dataset, and each sampling unit has the same probability of being selected. Next, we compute the statistic of interest, $M^{b}$, for each bootstrap sample, $b$. According to Hall (1994), the 95 percent bootstrap confidence interval of the statistic is

$$
\operatorname{Pr}\left(2 \widehat{M}^{c}-M_{0.975}^{b} \leq M \leq 2 \widehat{M}^{c}-M_{0.025}^{b}\right)=\frac{100-2 \alpha}{100}
$$

In equation (5), $\widehat{M}^{c}$ denotes the bootstrap bias-corrected statistics, $\widehat{M}^{c}=\widehat{M}-$ bias, with bias $=\frac{1}{B} \sum_{b=1}^{B} M^{b}-\widehat{M}$, and $\widehat{M}$ denotes the statistic from the original sampling distribution (point estimate).

\section{Results}

Our empirical exercise proceeds from the general to the specific. We start with an assessment of inequality within Europe, i.e., for the EA-10 and EU-22. Inequality is measured by the Theil and the Gini index. Next, indices from the European distribution are decomposed as described in the previous section. Finally, we show the results from the binational distributions. 


\subsection{EU-wide distribution and its development over time}

Two central statistics determine living standards in Europe: first, the "size of the cake", that is, average per capita PPP-EI, and second, the distribution of per capita PPP-EI.

Figure 5 provides average PPP-Els within the EA-10 and the EU-22. In this and all subsequent Figures, solid lines connect point estimates and vertical spikes indicate the 95 bootstrap confidence interval. For both areas, we find an inter-temporal rise in average PPP-EI, particularly from 2004 to 2007. Average PPP-El stagnates between 2007 and 2009 and rises again slightly from 2009 to 2011. Comparing the trend lines of the two regions reveals a marked difference in living standards. In year 2004, mean PPP-EI is about 15,470 EUR in the EA-10 and 14,525 EUR in the EU-22, a difference of almost 950 EUR. Over the period 2004 to 2008, mean PPP-El rises for both sets of Member States, with slightly higher growth rates in the EA-10 (2004-8 total growth rate: $+17.5 \%$; EU-22: $+14.8 \%)$. Since the financial crisis, growth rates have been markedly lower, particularly in the EU-22 (2008-11 total growth rate: $+2.8 \%$; EA-10: $+2.5 \%$ ). As a result, disparities in average living standards between the EA-10 and the EU-22 have increased over time: Mean PPP-EI in 2011 was about 18,640 EUR in the EA-10 and 17,490 EUR in the EU-22, meaning that the income gap has widened since 2004 by another 200 EUR.

\section{Figure 5 about here}

Figure 6 provides Gini and Theil indices from the EA-10 (left graph) and EU-22 distributions (right graph). ${ }^{7}$ Black lines connect Gini indices; grey lines connect Theil indices. Both indices indicate that in 2004, inequality in the EA-10 is significantly lower than in the EU-22 wide PPP-El distribution. As an example, the 2004 Gini indices differ by about 3 percentage points (EA-10: 0.297; EU-22: 0.327). In the following years, inequality within the EA-10 rises moderately: the Gini (Theil) index increases from 0.297 (0.125) in 2004 to 0.317 (0.143) in 2011. The increase over the two years 2010 to 2011 is particularly striking. For the EU-22, inequality decreases slightly before the crisis, and remains rather stable thereafter. Thus, between 2004 and 2011, the Gini (Theil) index decreases from 0.327 (0.176) to 0.311 (0.158).

Figure 6 about here

\footnotetext{
${ }^{7}$ Confidence intervals in Figure 6 are narrow, explaining why the vertical spikes appear as dots.
} 
Next we turn to the inequality decomposition by Member States. The first set of results is summarized by means of four graphs in Figure 7. The graphs in the left (right) column provide the results for the EA-10 (EU-22). The graphs in the first row show the Gini's three subcomponents, the Gini within, the Gini between, and the overlap. The graphs in the second row show the Theil two subcomponents, the within and the between. All subcomponents of an index are expressed in percent of the total index, thus adding up to 100.

We comment on the EA-10 first. In year 2004, the Theil within component makes up the majority of overall inequality, 93.4 percent. The dominant role of the within component is not astonishing, given the similarity of living standards (as captured by mean PPP-EI) across the EA-10. The similarity is mirrored by the Gini's overlap component, contributing 61.3 percent to the overall $\mathrm{Gini}^{8}{ }^{8}$ and the Gini within component, contributing 18.1 percent. Disparities between EA-10 countries enlarge over time. This can be seen from the increasing Theil-between (Gini-between) share. This share increases from 6.6 percent (20.6 percent) in 2004 to 12.2 percent (30.3) in 2011. The rising disparities are also reflected in smaller overlaps of income ranges: the Gini-overlap component declines from 61.3 percent in 2004 to 51.7 percent in 2011. Again, the changes are most pronounced in the last two observation periods.

We next turn to the EU-22. Because here living standards are more disparate, the between component plays a more important role: It contributes 29.8 percent to the 2004 Theil index, and almost 50 percent to the $2004 \mathrm{Gini}$ index. The inter-temporal patterns are rather different compared to the EA-10: Between 2004 and 2008, the share of Theil between falls from 29.8 to 21.6 percent and varies around 21 percent afterwards. The trend for the Gini between is basically the same. Apparently, declining average living standards in the crisis countries towards the standards in the poorer EU-22 Member States have reduced the inequalities between these countries. Further, the Gini's overlap offers another interesting insight: its share in total inequality increases from 41.9 percent in 2004 to 48.5 percent in 2008, suggesting a convergence of living conditions up to the crisis. In recent years, however, the pattern has been reversed: the contribution of the overlap declines to 46.8 percent, suggesting a divergence in living conditions.

\section{Figure 7 about here}

Next we address the key drivers of Europe-wide inequality, namely cross-country differences in average PPP-Els, and the extent of inequality in the country-specific distributions. We start with the country-specific PPP-Els, provided in Figures 8a (EA-10) and 8b (EU-22 without EA10).

\footnotetext{
${ }^{8}$ Gini's overlap component is zero if the subgroup income ranges do not overlap.
} 


\section{Figures $8 a$ and $8 b$ about here}

In the EA-10, three groups of countries can be distinguished. The first group (G1), consisting of AT, DE, FI, and FR, shows a robust upward trend of PPP-El. In the second group (G2), consisting of IT, NL, LU, and PT, PPP-El increases until 2007 and stagnates afterwards. In a third group (G3), ES and GR, PPP-El increases until 2008 and then declines. ${ }^{9}$ The decline of PPP-El in ES and GR, countries that ranked at the bottom of the EA-10 distribution, explains the increasing contribution of the between component to overall inequality (and the decreasing contribution of Gini's overlap component). For Luxembourg, PPP-EI tends to decrease slightly, but confidence intervals are too large to draw a final conclusion.

For the EU-22 countries without the EA-10, an analogous classification can be made with the following assignment. G1: CY, CZ, DK, HU, SI, and SK; G2: EE, LT, and PL; and G3: LV, SE, and UK. The decline is most pronounced in the UK. Possible explanations are the strong ties to the US economy and the important role of the financial sector there.

Finally, we turn to the inequalities at the Member State level. Results for the EA-10 are provided in Figure 9a, for the E-22 countries without the EA-10 in 9b. Overall, inequalities at the country level appear to have changed very little since 2004. Only in AT, ES, and DK has inequality increased slightly in recent years. The stability of the country-level inequalities shows that analyses on the Member State level alone are not sufficient to understand inequality in the European Union. This is because country-level inequalities do not reveal disparities between countries.

\section{Figures $9 a / b$ about here}

\subsection{Binational distributions}

This section addresses the binational distributions, revealing disparities in living standards across pairs of countries. The binational approach is interesting for two reasons. The first is technical: distributional changes within small countries are almost invisible in a multicountry framework that involves large countries. Second, assuming that "our" income relative to the income of "others" does not matter is at odds with psychological studies (e.g., Graham and Felton 2005, Frank 2005) which show that people not only care about their absolute income but also pay attention to their position in the income distribution.

\footnotetext{
${ }^{9}$ Interestingly, disposable equivalent incomes and national accounts (GDP per capita) show different trends in some countries. As pointed out in Milanovic (2006, p. 5), this difference "represents one of the most important areas for further research."
} 
To keep the analysis manageable, we confine our analysis to the EA-10 and the Theil index. This gives results for 45 binational distributions per wave. In the graphical presentation, we have arranged the results by country assignment, G1-G3 (see Section 4.1).

Figure 10a shows the results of the six binational distributions for all possible pairs of $\mathrm{G} 1$ countries (AT, DE, FI, FR). These countries have shown a robust upward trend of average PPP-El. The Theil index indicates that disparities within the binational distributions increased slightly from 2004-11. This increase is driven almost $1: 1$ by the increase in the Theil within component. Because average PPP-Els evolved similarly for all G1 countries and average living standards are similar, the Theil between component plays a negligible role, as expected by construction.

\section{Figure 10a about here}

For the six binational distributions for pairs of $G 2$ countries (IT, LU, NL, and PT), the results are more heterogeneous as can be seen from Figure 10b. In these countries, average PPP-EI increased until 2007 and stagnated afterwards. For the binational distributions (NL and PT) and (LU and PT), the Theil index is slightly lower in the last compared to the first years of the observation period. For both binational distributions, the between component of the Theil index is larger than for the binational distributions from the G1 countries. However, it still contributes only four percentage points to total inequality. As mean PPP-Els within the G2 group follow a similar inter-temporal path, the between component changes little over time, and it is again the changes in the within component that determine the evolution of overall inequality. For the remaining four binational distributions for G2, the Theil index and its subcomponents change little over the observation period.

\section{Figure 10b about here}

For the two G3 crisis countries, Spain and Greece, provided in Figure 10c, we find a slight upward trend in overall inequality. To a great extent, the increase is driven by the increase of the Theil within component. However, the severe recession in Greece also widened the disparity in average living standards, leading to a rise in the between component between 2010 and 2011.

\section{Figure 10c about here}


Next we turn to the binational distributions obtained by combining the distribution of one $\mathrm{G} 1$ and one $\mathrm{G} 2$ country. This gives 16 distributions. For seven of these distributions, provided in Figure 11a, Theil indices and their subcomponents hardly change over the entire observation period. These distributions are: (AT and IT), (AT and LU), (AT and NL), (FI and IT), ( $\mathrm{FI}$ and $\mathrm{LU}),(\mathrm{FI}$ and $\mathrm{NL}$ ), as well as (FR and IT). For the nine remaining distributions, provided in Figure 11b, inequality is usually slightly higher after the crisis years. For (AT and PT), (FI and PT), and (FR and PT) the between component is the driver of this inequality increase, while else it is the within component.

\section{Figures 11a and 11b about here}

Finally, we turn to the 16 binational comparisons including one of the G3 countries, Spain and Greece, with one $\mathrm{G} 1$ or G2 country. For the eight (G1 and G3) distributions, provided in Figure 12a, we see a marked increase in the Theil index in the post-crisis period, and it is the between component that can be identified as the key driver. As explained above, this component remains unobserved in analyses that deal with inequalities at the national level. For the eight (G2 and G3) distributions, provided in Figure 12b, the picture is less clear. For the four binational distributions involving one rich $\mathrm{G} 2$ country ( $\mathrm{LU}$ or $\mathrm{NL}$ ), the picture is similar to the (G1 and $G 3$ ) distributions. For three out of the four distributions remaining, the between component of the Theil index hardly changes for (ES and IT), (ES and PT), and (GR and PT). Thus, only the within-component can cause a change in inequality: for (ES and IT), (ES and PT), its post-crisis increase raises the Theil index; for (GR and PT) its decrease slightly lowers post-crisis inequality. Only for (GR and IT) do we find a slight increase of the Theil index and its between component after the crisis.

\section{Figures $12 \mathrm{a}$ and $12 \mathrm{~b}$ about here}

\section{Conclusion}

Current research on inequality addresses inter- and intra-generational mobility, poverty, equality of opportunities, and the interrelations between inequality and economic development, societal cohesion, and democracy. Possibly the two most hotly debated inequality topics today is the relationship between economic development and inequality and the interrelationships between economic crises and inequality.

The recent financial and economic crisis in Europe, accompanied by a period of fiscal consolidation, low GDP growth, and high unemployment in several EU Member States, has 
raised concerns about socioeconomic disparities in the EU and especially in its common currency area. Although the EU claims to be working towards convergence and social cohesion among its Member States, in the public perception, the countries of the EU are growing further apart.

This study has provided empirical evidence on the EU-wide distribution of living standards, measured in terms of PPP-adjusted equivalent disposable income, and how it changed in the years before and after the financial crisis. Harmonized EU-SILC household data served as our empirical basis. We found a moderate rise in inequality in the EA-10 wide distribution up to 2011. This is true for both inequality indices used in the present study, the Theil and the Gini index. The increase in inequality is particularly noteworthy during the last two waves in the EA-10. In the EU-22, the indices indicate a slight decrease of inequality before the crisis, and stagnating inequality afterwards. Widening disparities across Member States are the driving force behind the rise of inequality within the EA-10, and not rising inequalities within the countries.

In sum, focusing on national-level estimates of inequality-and comparing their evolution over time-neglects one important aspect: widening differences in average living standards, particularly between the crisis countries Greece and Spain on the one hand and economically strong countries such as Germany, Austria, and Luxembourg on the other. 


\section{References}

Avram, S., Figari, F., Leventi, C., Levy, H., Navicke, J., Matsaganis, M., Sutherland, H. (2013): The Distributional Effects of Fiscal Consolidation in Nine EU countries, Euromod Working Paper, EM2/13.

Biewen, M. (2002): Bootstrap Inference for Inequality, Mobility and Poverty Measurement, Journal of Econometrics, 108, 317-342.

Brandolini, A. (2007): Measurement of Income Distribution in Supranational Entities: The Case of the European Union, Banca d'Italia, Temi di discussione, 623.

Dagdeviren, H. (2014): The 2008 Financial Crisis and Inequality in Europe: Impact through Market and Redistribution, University of Hertfordshire, Business School, Paper Submitted to the Progressive Economy Annual Forum, Brussels.

Dauderstädt, M., and Keltek, C. (2012): Eurocrisis. Inequality is Growing Again in Europe, Friedrich-Ebert-Stiftung.

De Beer, P. (2012): Earnings and Income Inequality in the EU during the Crisis, International Labour Review, 151, 313-331.

Eurostat (2014): Symbols and abbreviations, Eurostat Tutorial: http://epp.eurostat.ec.europa.eu/statistics explained/index.php/Tutorial:Symbols a nd abbreviations.

Eurostat (2010): Income and Living Conditions in Europe, Eds.: Atkinson, A.B., and Marlier, E., European Union: Belgium.

Frank, R.H. (2005): Positional Externalities Cause Large and Preventable Welfare Losses, American Economic Review Papers and Proceedings, 95(2), 137-151.

Georgopoulos, D., Papadogonas, T., and Sfakianakis, G. (2012): Factors Related to the Depth of the Latest Crisis for EU-27 Countries - The Key Role of Relative Inequality/Poverty, Economics Letters, 116, 308-311.

Goedemé, T. (2013): How much Confidence can we have in EU-SILC? Complex Sample Designs and the Standard Error of the Europe 2020 Poverty Indicators, Social Indicators Research, 110, 89-110.

Grabka, M. (2015): Income and Wealth inequality after the financial crisis-the case of Germany, Empirica - Journal of European Economics, (forthcoming).

Graham, C., and Felton, A. (2005): Does Inequality Matter to Individual Welfare? An Exploration Based on Household Surveys in Latin America, Center on Economic and Social Dynamics, Working Paper Series, 38, Brookings Institutions. 
Guvenen, F., Ozkan, S., and Song, J. (2014): The Nature of Countercyclical Income Risk, Journal of Political Economy, 122, 621-660.

Hall, P. (1994). Methodology and Theory for the Bootstrap. In Engle. R. and D. McFadden (Eds.), Handbook of Econometrics 4. Amsterdam: Elsevier, 2341-2381.

Hellebrandt, T. (2014): Income Inequality Developments in the Great Recession, Peterson Institute for International Economics.

lacovou, M., Kaminska, O., and Levy, H. (2012): Using EU-SILC data for cross-national analysis: strengths, problems and recommendations, ISER Working Paper Series, 3.

Jenkins, S., Brandolini, A., Mickelwright, J. and Nolan B. (eds.) (2013): The Great Recession and the Distribution of Household Income, Oxford University Press, Oxford, UK.

Kuznets, S. (1965): Economic Growth and Structure. New York: Norton.

Lohmann, H. (2011): Comparability of EU-SILC survey and register data: The relationship among employment, earnings and poverty, Journal of European Social Policy 21, $37-$ 54.

Milanovic, B. (2006): Global Income Inequality: What it is and Why it Matters, World Bank Policy Research Working Paper, 3865.

Pogge, T.W., and Reddy, S. (2002): Unknown: The Extent, Distribution, and Trend of Global Income Poverty, http://www.columbia.edu/ sr793/povpop.pdf.

Roine, J., Vlachos, J., and Waldenström, D. (2009): The Long-run Determinants of Inequality: What Can We Learn from Top Income Data?, Journal of Public Economics, 93, 974988.

Schröder, C., and Bönke, T. (2012): Country Inequality Rankings and Conversion Schemes. Economics, The Open-Access, Open-Assessment E-Journal, 6(2012-28), 1-44, http://dx.doi.org/10.5018/economics-ejournal.ja.2012-28.

Singer, P. (2002): One World: The Ethics of Globalization, New Haven, USA: Yale University Press.

TFEU - Consolidated Version of the Treaty on the Functioning of the European Union (2012), Official Journal of the European Union, 326(47).

Theodoropoulou, S., and Watt, A., (2011): Withdrawal Symptoms. An Assessment of the Austerity Packages in Europe, Bruxelles, ETUI. 


\section{Tables}

Table 1. Breakdown of countries

\begin{tabular}{|c|c|c|c|c|c|}
\hline Country & $\begin{array}{c}\text { Country } \\
\text { code }\end{array}$ & $\begin{array}{c}\text { EU } \\
\text { membership }\end{array}$ & $\begin{array}{c}\text { EA } \\
\text { membership }\end{array}$ & $\begin{array}{c}\text { Missing } \\
\text { waves }\end{array}$ & $\begin{array}{c}\text { Average } \\
\text { sample size }\end{array}$ \\
\hline Austria & AT & 1995 & 1999 & - & 5901 \\
\hline Belgium & $\mathrm{BE}$ & 1958 & 1999 & 2012 & 5839 \\
\hline Cyprus & $\mathrm{CY}$ & 2004 & 2008 & - & 3639 \\
\hline Czech Republic & $\mathrm{CZ}$ & 2004 & - & - & 8507 \\
\hline Denmark & DK & 1973 & - & - & 5562 \\
\hline Estonia & $\mathrm{EE}$ & 2004 & 2011 & - & 4887 \\
\hline Finland & $\mathrm{FI}$ & 1995 & 1999 & - & 10280 \\
\hline France & FR & 1958 & 1999 & - & 10492 \\
\hline Germany & $\mathrm{DE}$ & $1958 / 1990$ & 1999 & - & 13088 \\
\hline Greece & $\mathrm{GR}$ & 1981 & 2001 & - & 5962 \\
\hline Hungary & $\mathrm{HU}$ & 2004 & - & - & 9169 \\
\hline Ireland & $\mathrm{IE}$ & 1973 & 1999 & 2012 & 5160 \\
\hline Italy & IT & 1958 & 1999 & - & 19943 \\
\hline Latvia & LV & 2004 & 2014 & - & 5223 \\
\hline Lithuania & LT & 2004 & - & - & 4861 \\
\hline Luxemburg & LU & 1958 & 1999 & - & 4369 \\
\hline Malta & MT & 2004 & 2008 & 2005-2007 & 3764 \\
\hline Netherlands & $\mathrm{NL}$ & 1958 & 1999 & - & 9706 \\
\hline Poland & PL & 2004 & - & - & 13651 \\
\hline Portugal & PT & 1986 & 1999 & - & 4887 \\
\hline Slovakia & SK & 2004 & 2009 & - & 5114 \\
\hline Slovenia & SI & 2004 & 2007 & - & 8893 \\
\hline Spain & ES & 1986 & 1999 & - & 12500 \\
\hline Sweden & SE & 1995 & - & - & 6790 \\
\hline United Kingdom & UK & 1973 & - & - & 8970 \\
\hline
\end{tabular}

Note. Average sample size across all available waves, not weighted. Authors' calculations. Source: EU-SILC. 


\section{Figures}

Figure 1. Change in GDP in selected EU countries

DE

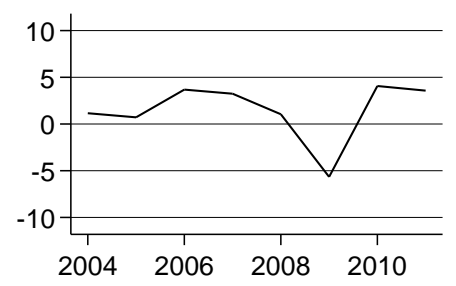

FR

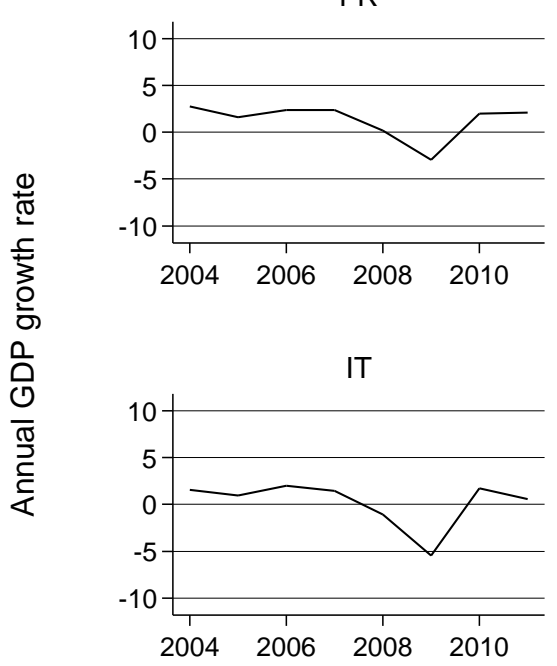

PT

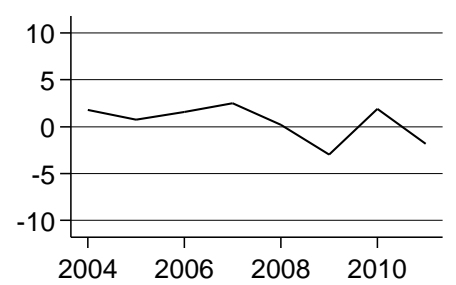

ES

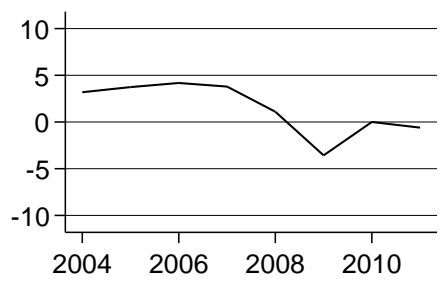

GR

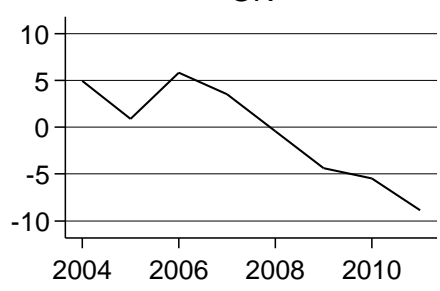

LU

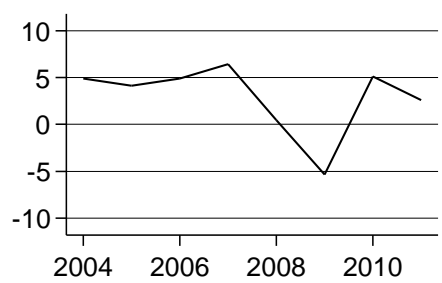

PL

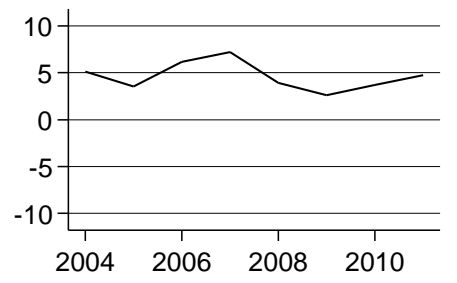

year
$\mathrm{FI}$

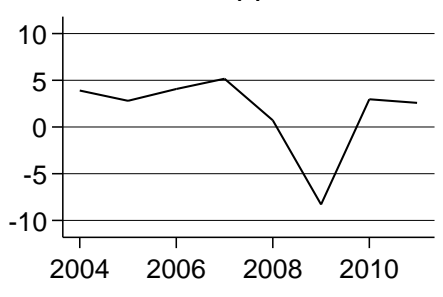

HU

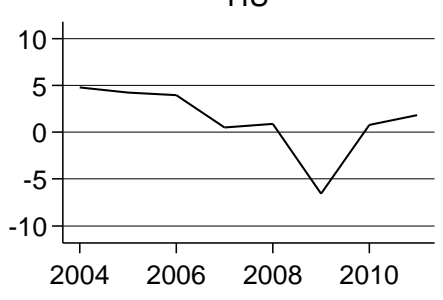

$\mathrm{NL}$

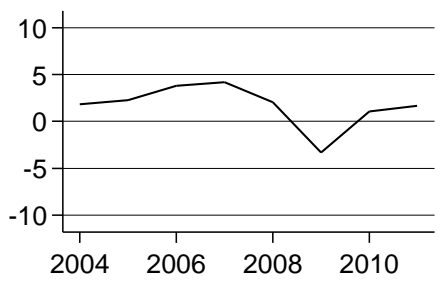

UK

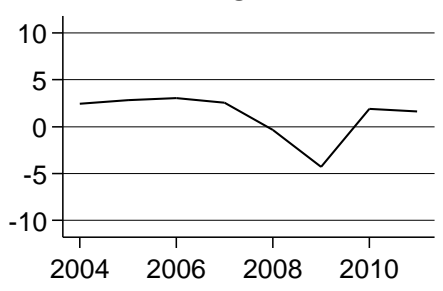

Note. Annual GDP growth rate at market prices in \% based on constant local currency. World Bank Data online (download: 12/27/2014). Authors' presentation. 
Figure 2a. Disposable income in the EA-10 countries

AT
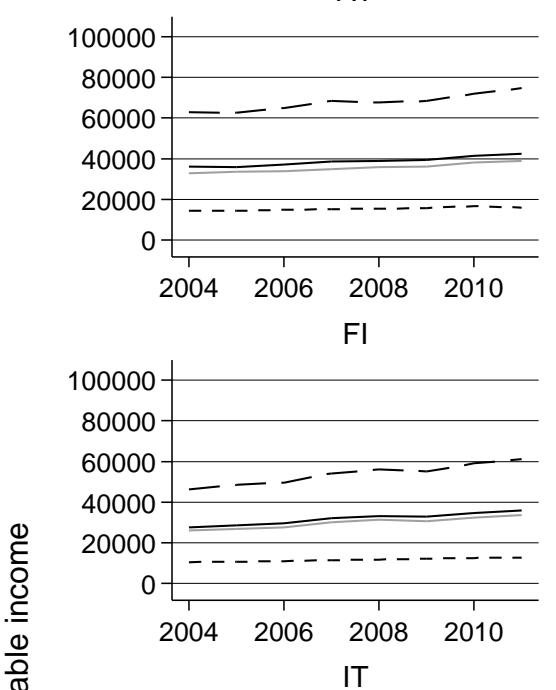

कू

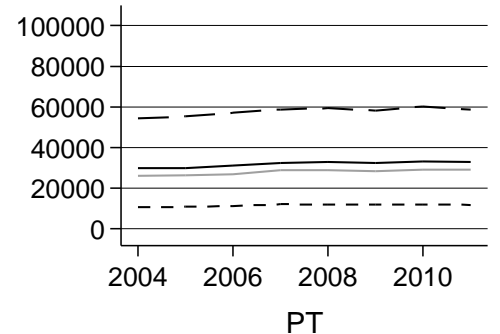

$\mathrm{DE}$
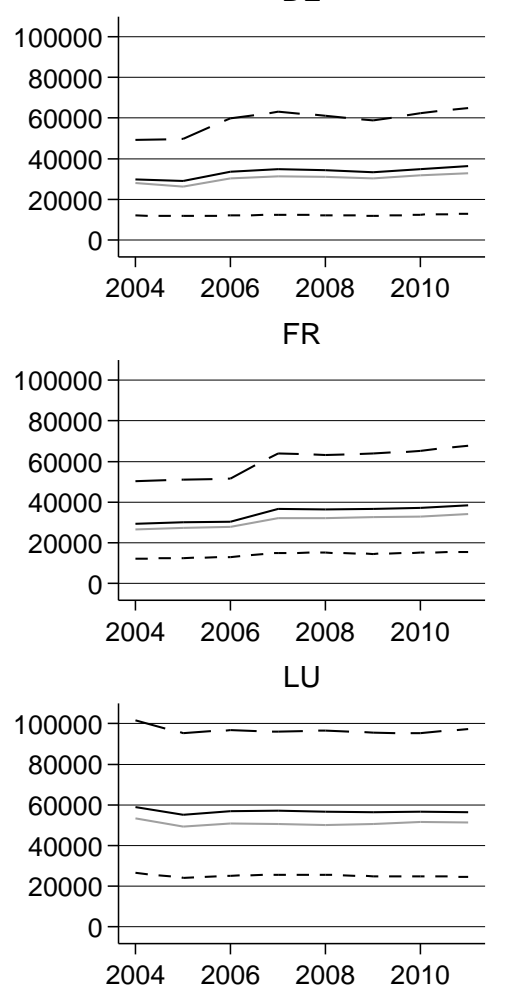

ES

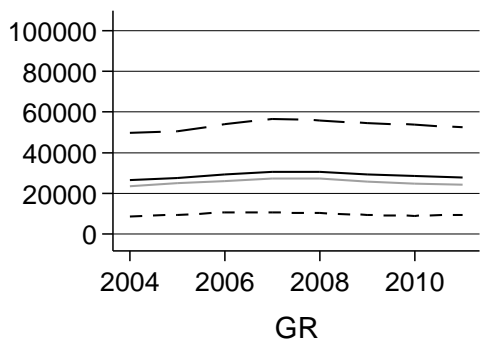

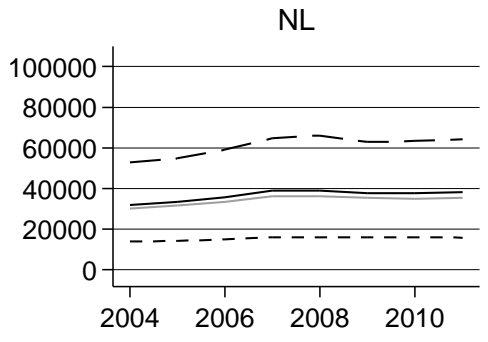

year

$\longrightarrow$ mean $=-p$ p10 - p50 - p90

Note. Annual disposable income. Database is EU-SILC (see Section 2.1 for details). Authors' calculations. 
Figure 2b. Disposable income in the EU-22 countries without EA-10

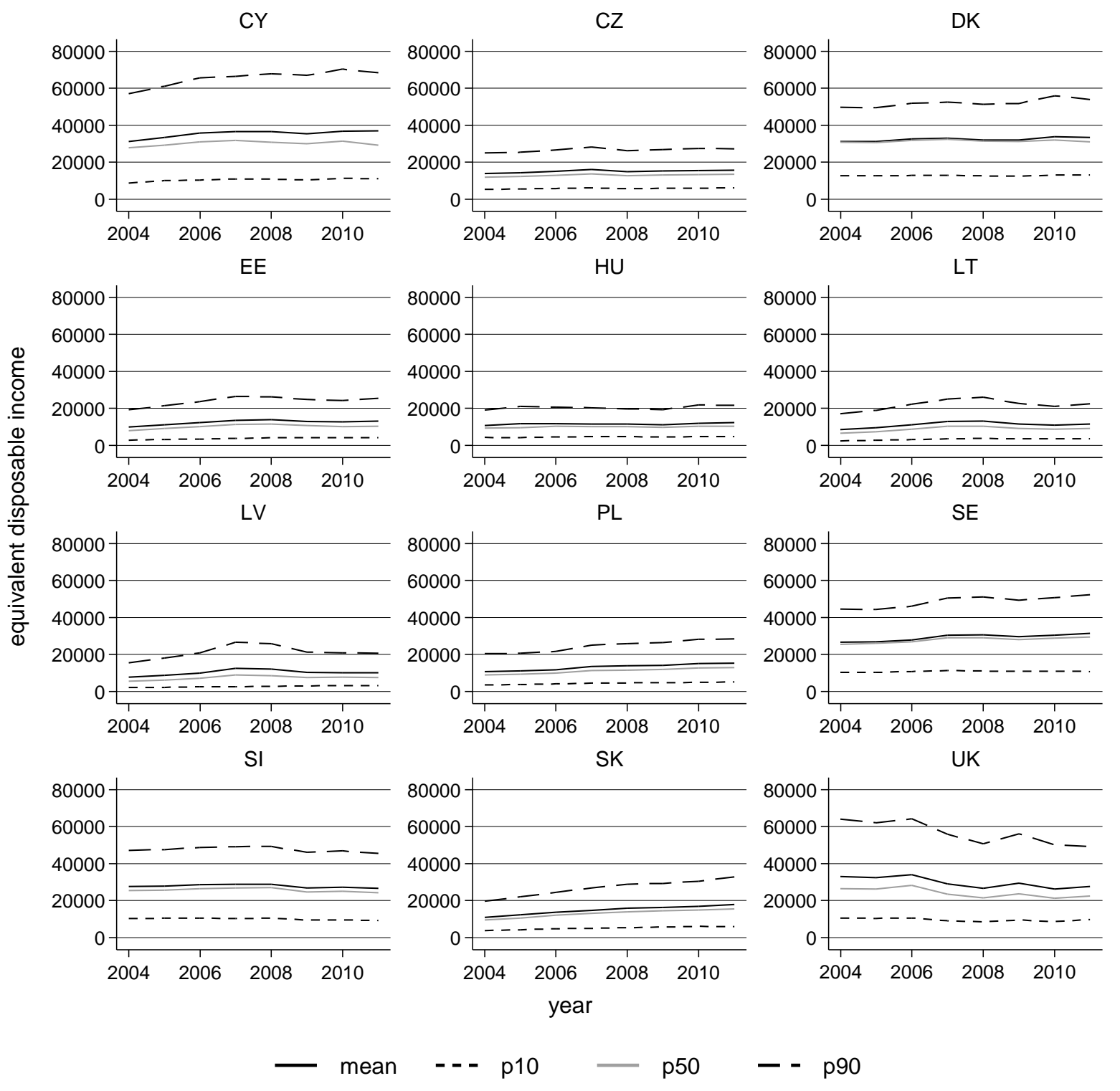

Note. Annual disposable income. Database is EU-SILC (see Section 2.1 for details). Authors' calculations. 
Figure 3. Density of equivalent disposable income for the EA-10 and EU-22 in 2005 and 2012

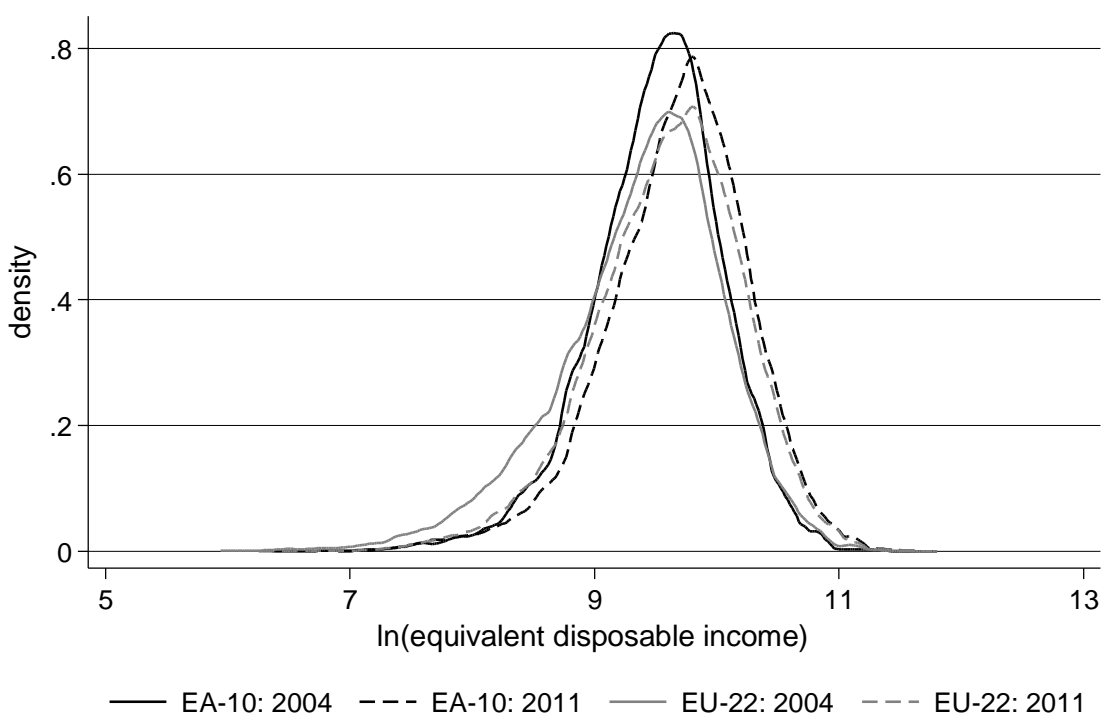

Note. Overall equivalent income distributions for EA-10 / EU-22. Database is EU-SILC (see Section 2.1 for details). Authors' calculations. 
Figure 4a. Densities of equivalent disposable income by EA-10 country

AT

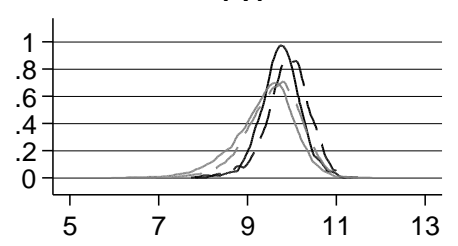

$\mathrm{FI}$

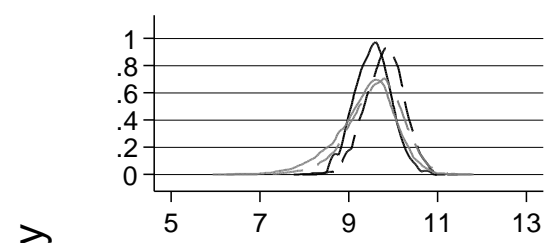

$\frac{\frac{7}{0}}{\frac{1}{0}}$

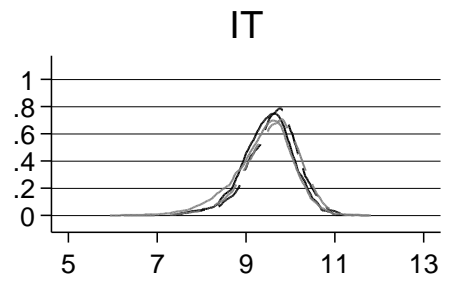

PT

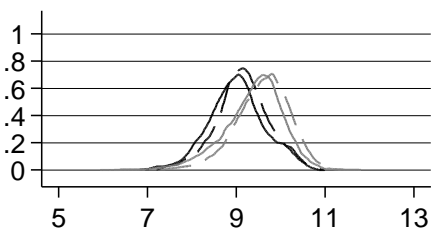

\section{In(equivalent disposable income)}

Memberstate: 2004 — - Memberstate: 2011 EU-22: $2004--$

EU-22: 2011

Note. Equivalent income distributions by country of EA-10. Database is EU-SILC (see Section 2.1 for details). Authors' calculations. 
Figure $\mathbf{4 b}$. Densities of equivalent disposable income by EU-22 country without EA-10
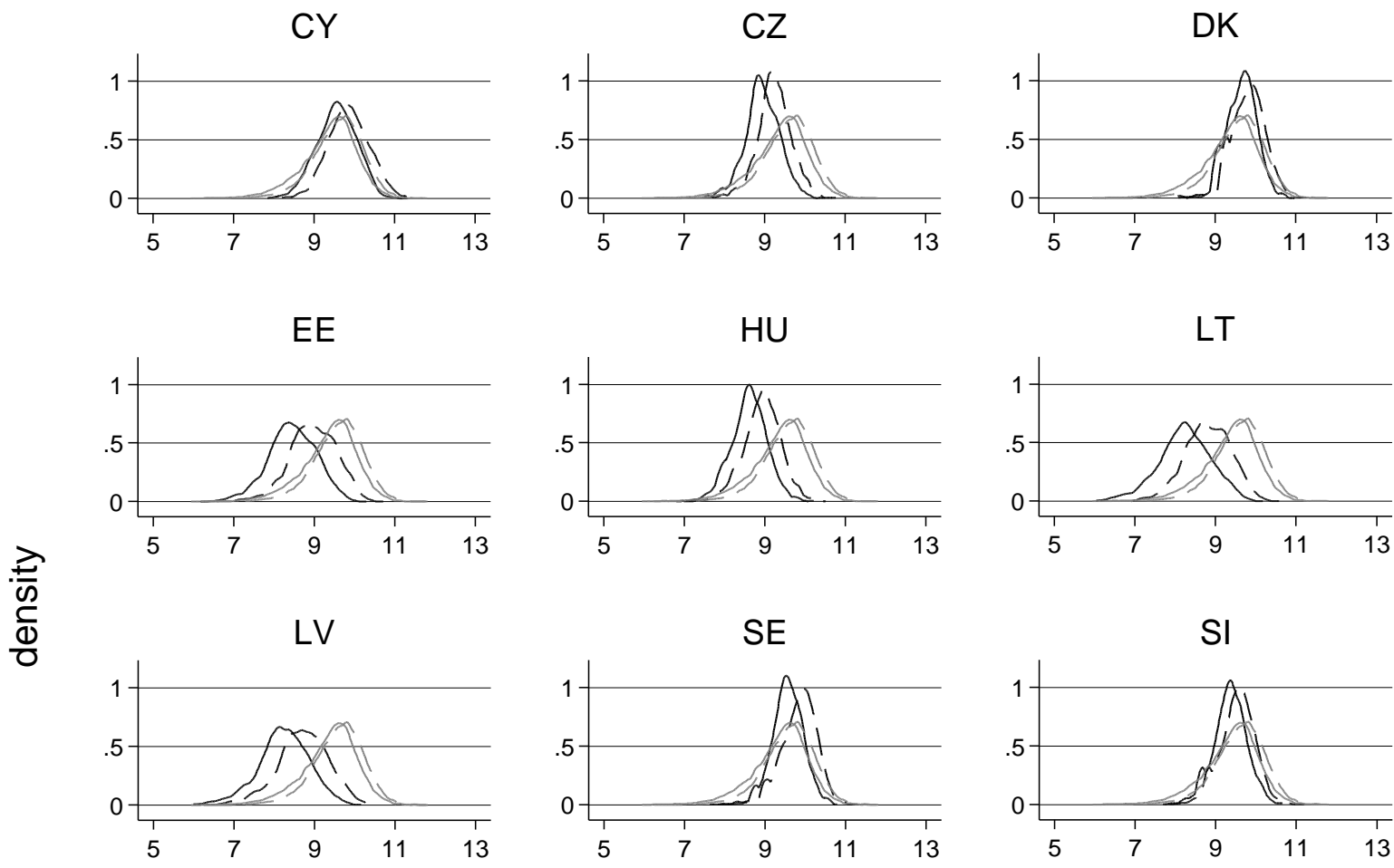

$\mathrm{HU}$

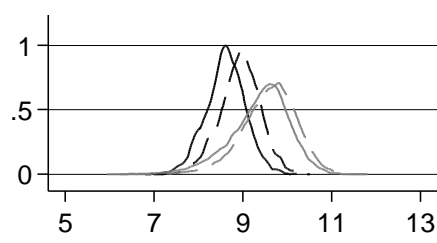

LT
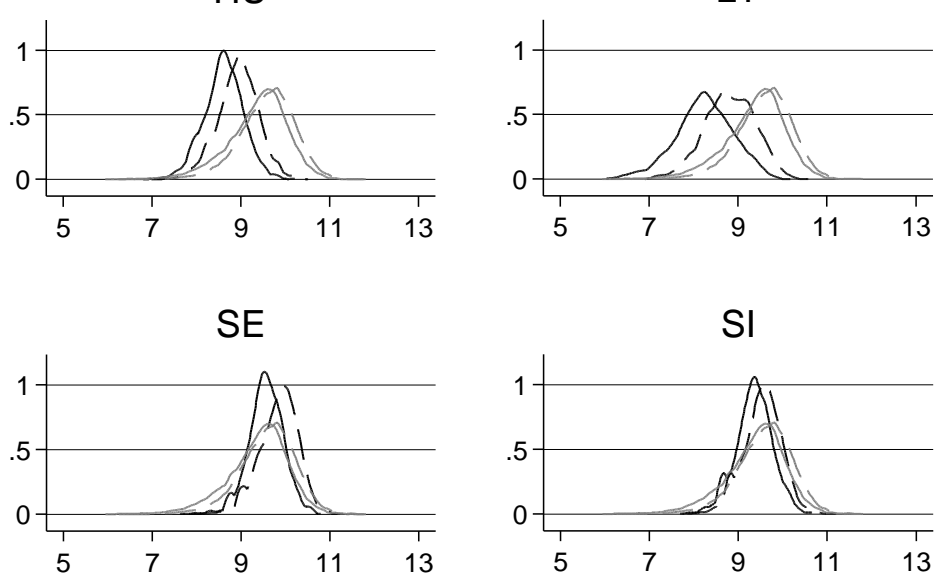

SI

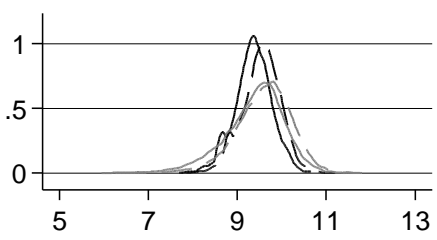

SK

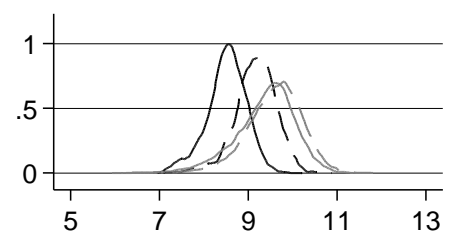

PL

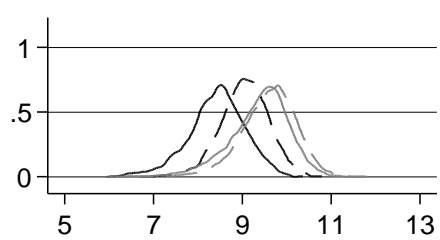

UK

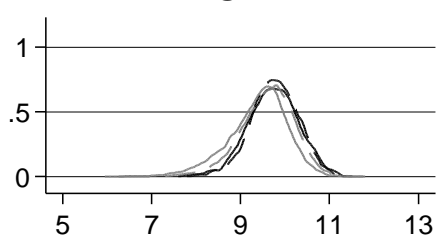

In(equivalent disposable income)

Memberstate: 2004 — - Memberstate: 2011 EU-22: 2004 - - EU-22: 2011

Note. Equivalent income distributions by country of EU-22 \EA-10. Database is EU-SILC (see Section 2.1 for details). Authors' calculations. 
Figure 5. Average equivalent disposable income in EA-10 and EU-22

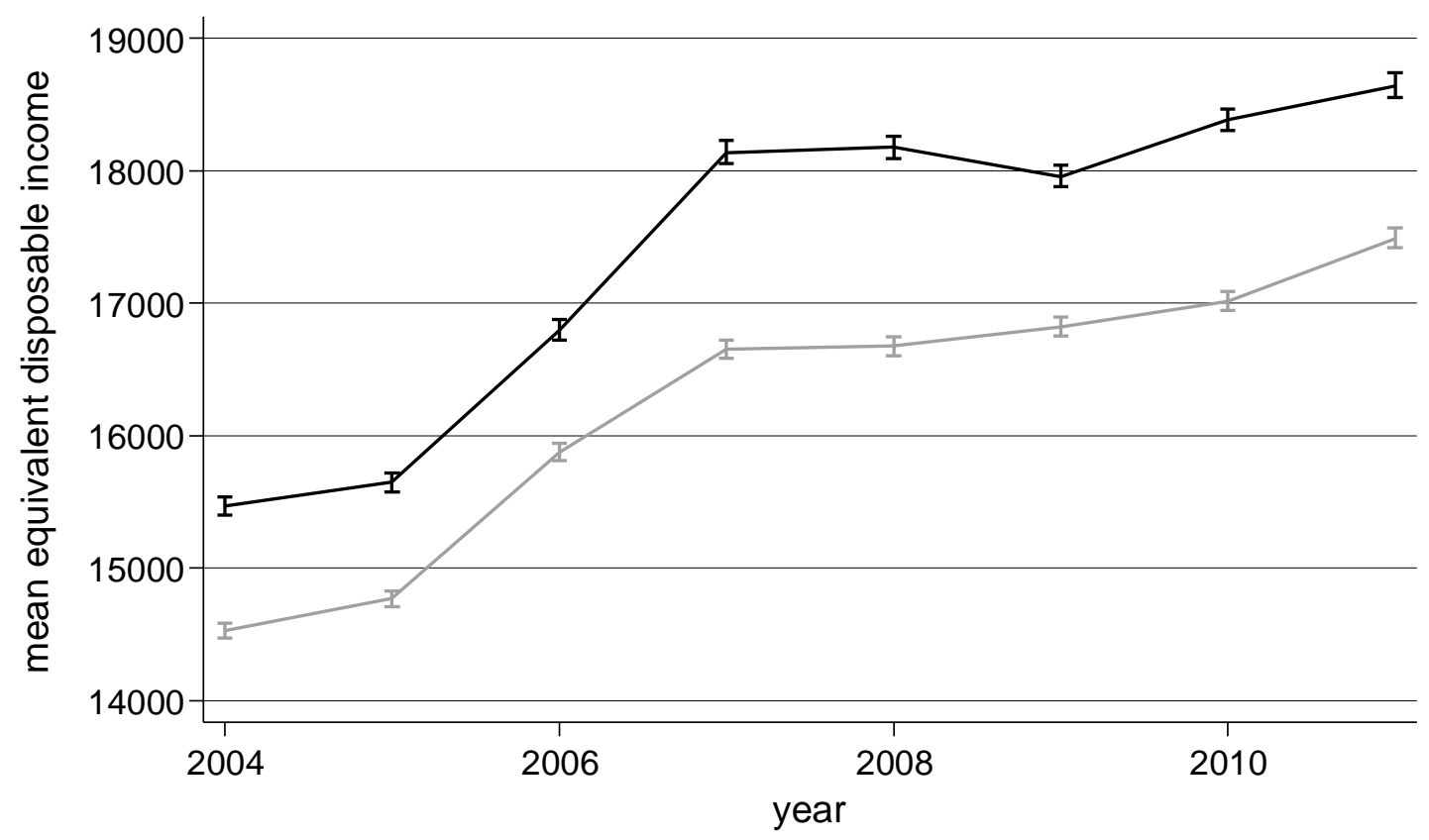

EA-10 EU-22

Note. Annual equivalent disposable income. Database is EU-SILC (see Section 2.1 for details). Authors' calculations.

Figure 6. Overall inequality in the EA-10 and EU-22

EA-10

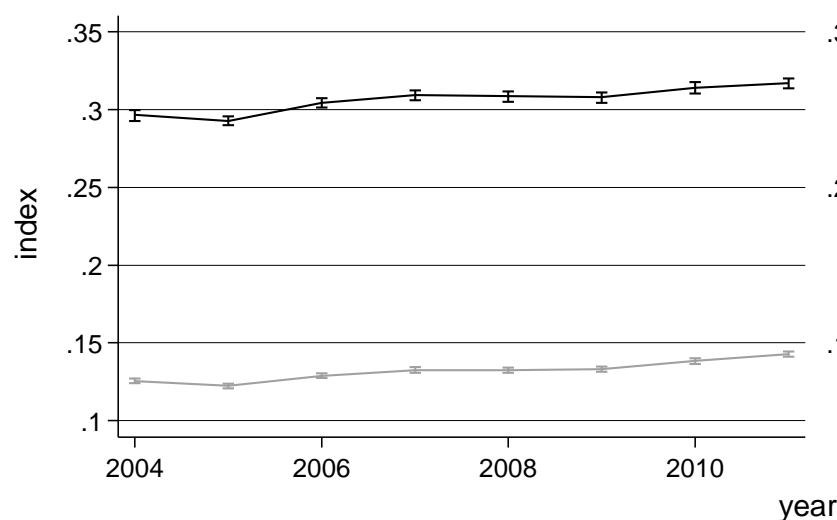

EU-22

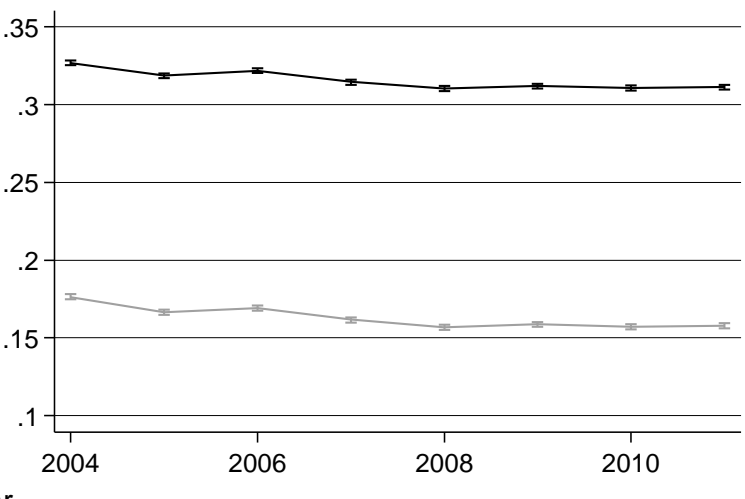

— Gini - Theil

Note. EA-10 / EU-22 inequality indices based on equivalent disposable income. Solid lines connect point estimates. Vertical spikes indicate 95 percent bootstrap confidence intervals. Gini: black line; Theil index: grey line. Database is EU-SILC (see Section 2.1 for details). Authors' calculations. 
Figure 7. Inequality decomposition

EA-10

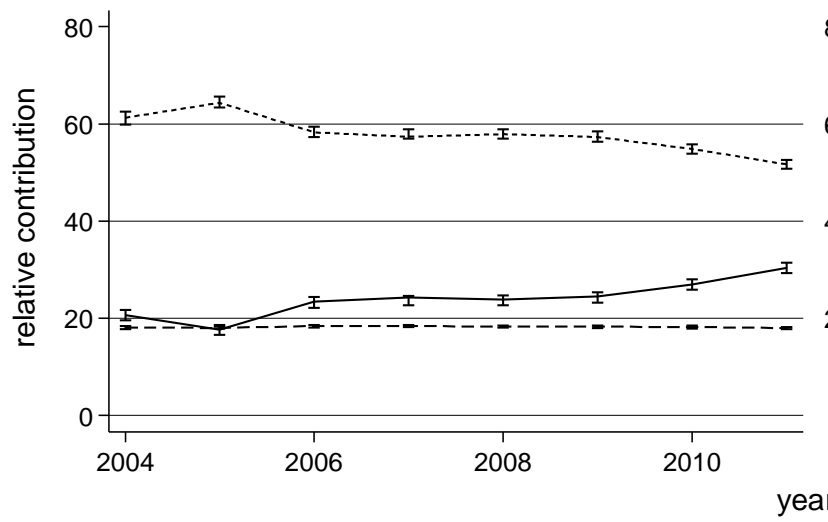

— Gini between - - - Gini within

EA-10

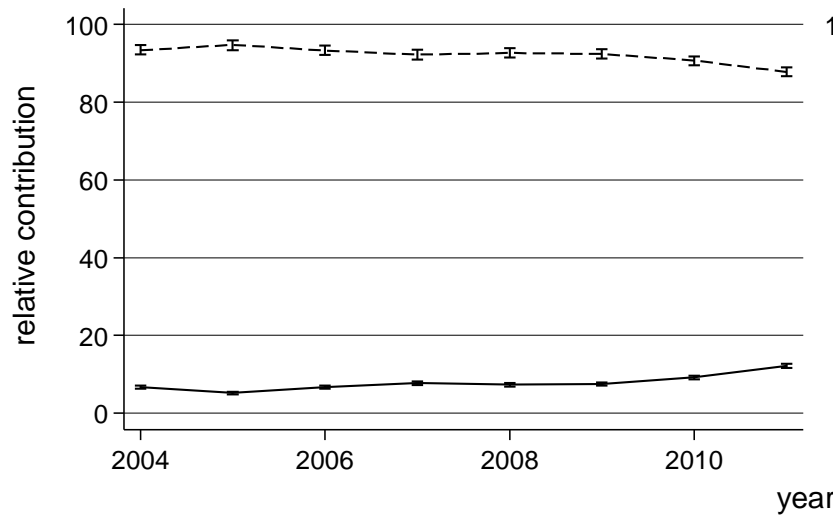

- Theil between
EU-22

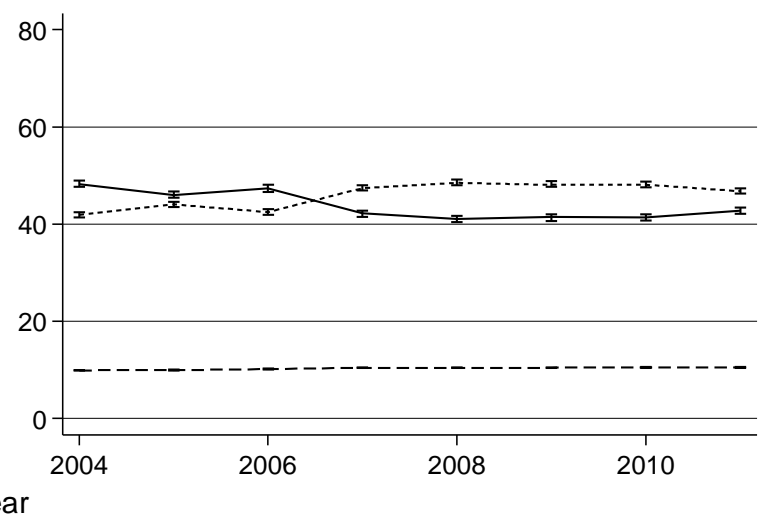

EU-22

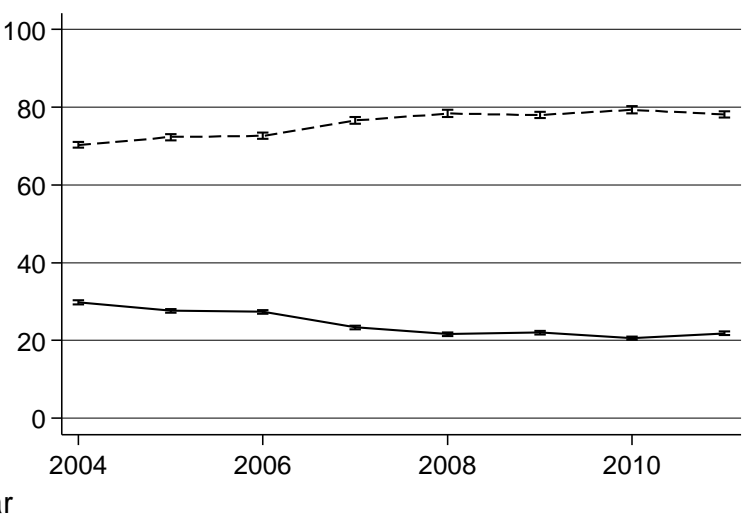

Note. Decomposition estimates of EA-10 / EU-22 wide inequality indices based on equivalent disposable income. Solid lines connect point estimates. Vertical spikes indicate 95 percent bootstrap confidence intervals. Database is EU-SILC (see Section 2.1 for details). Authors' calculations. 
Figure 8a. Average equivalent disposable income in the EA-10 countries
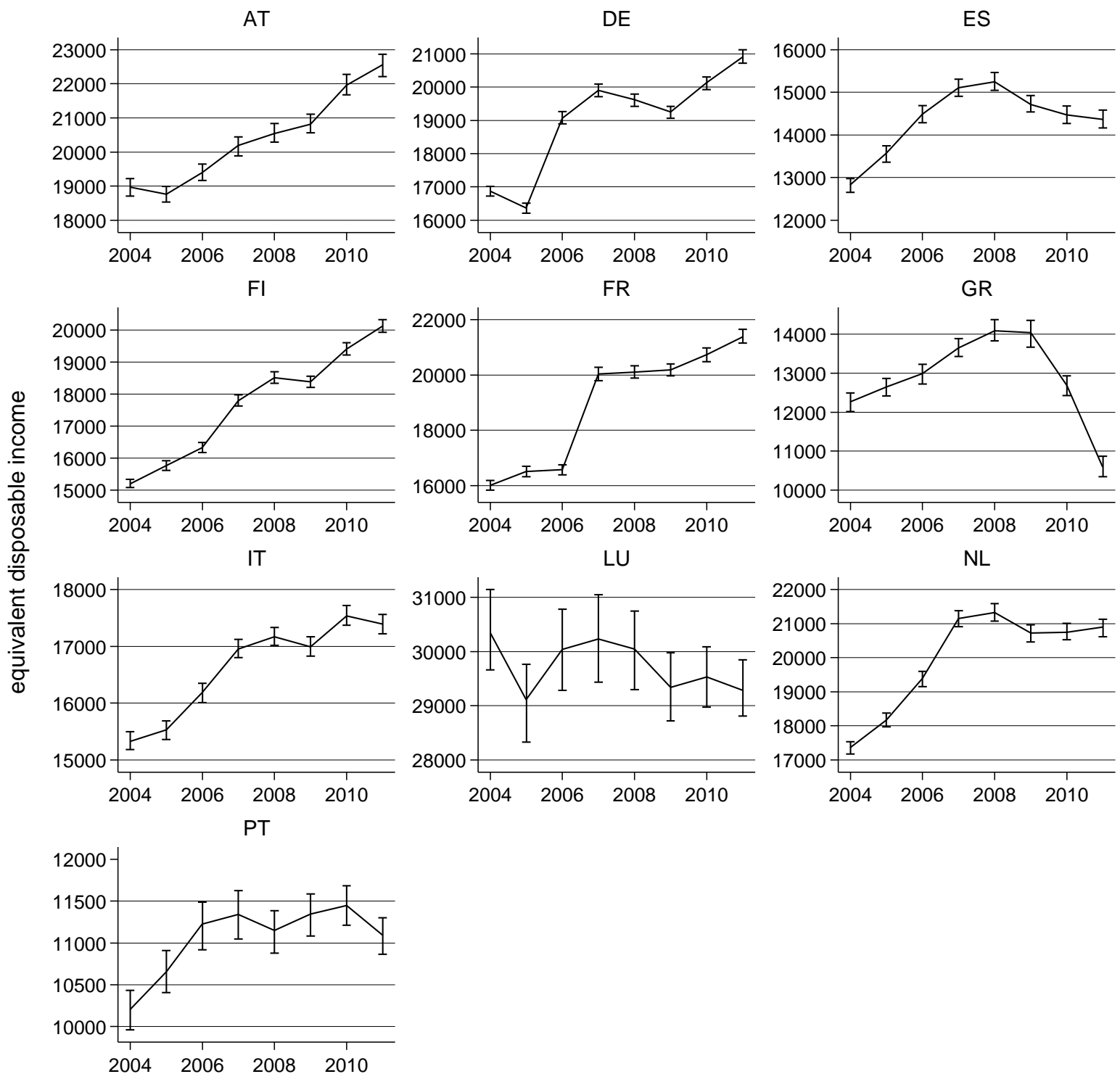

year

Note. Solid lines connect point estimates. Vertical spikes indicate 95 percent bootstrap confidence intervals. Database is EU-SILC (see Section 2.1 for details). Authors' calculations. 
Figure 8b. Average equivalent disposable income in the EU-22 countries without EA-10
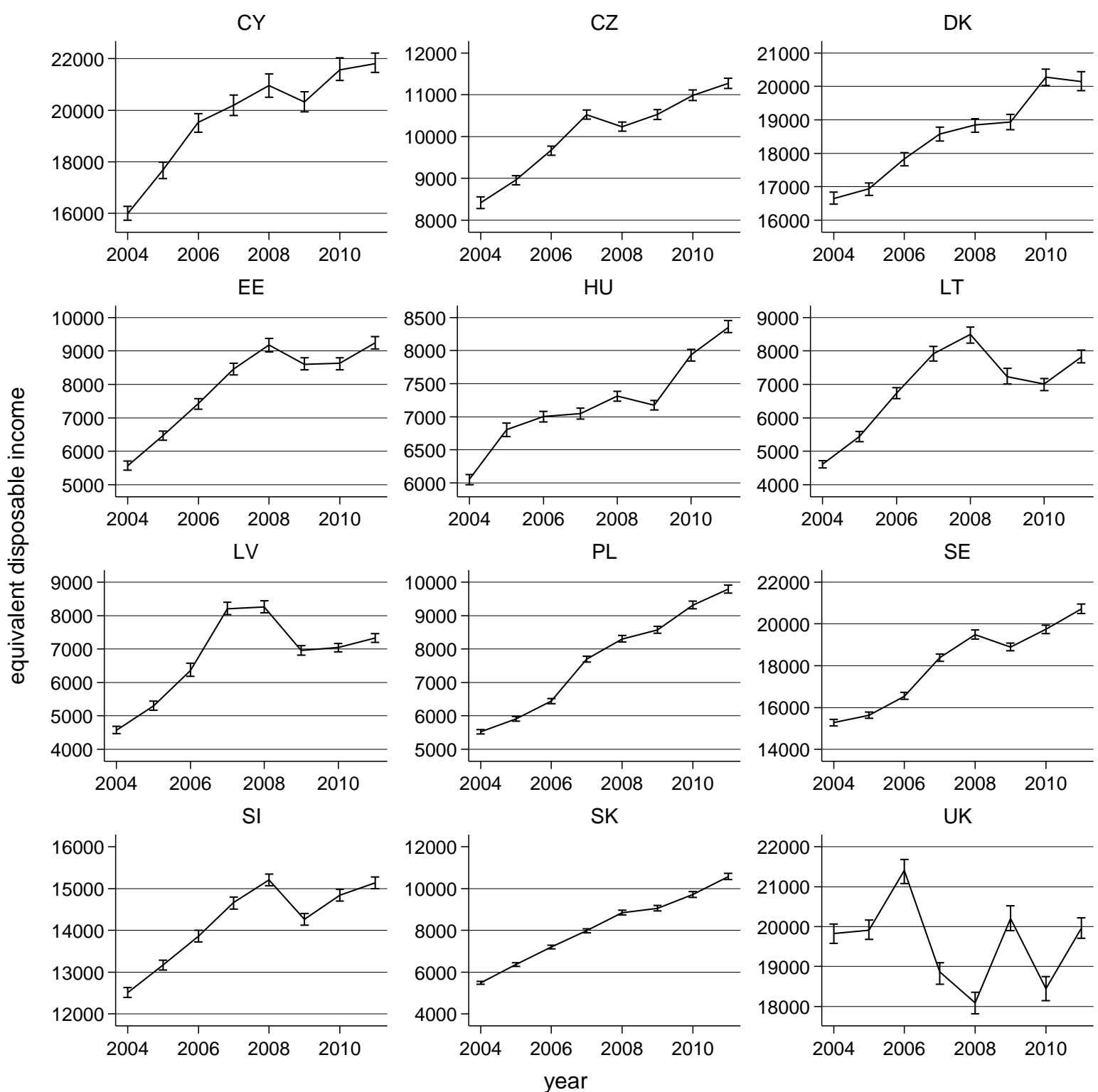

Note. Solid lines connect point estimates. Vertical spikes indicate 95 percent bootstrap confidence intervals. Database is EU-SILC (see Section 2.1 for details). Authors' calculations. 
Figure 9a. Inequality in the EA-10 countries

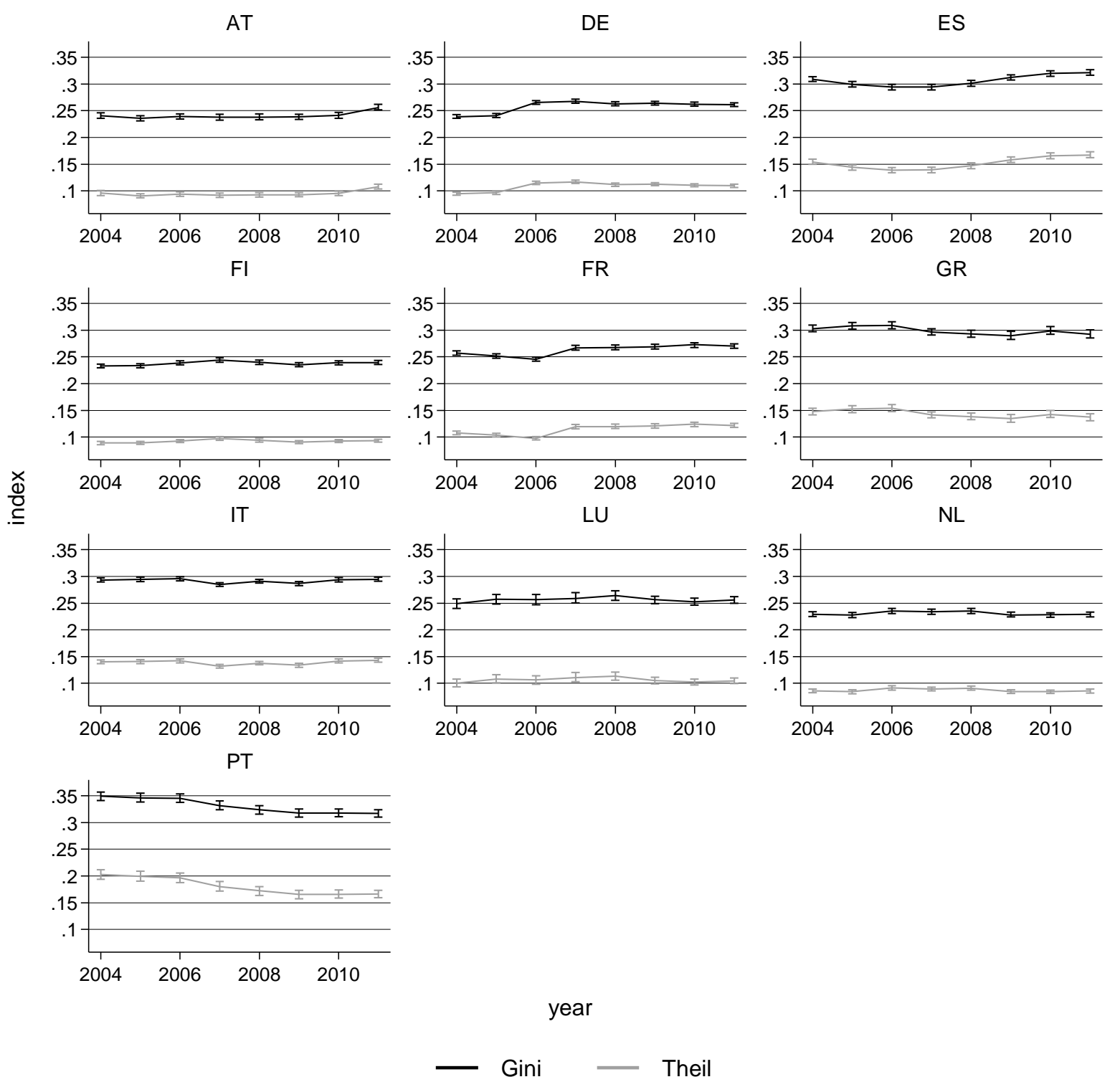

Note. Country-specific inequality indices based on equivalent disposable income. Solid lines connect point estimates. Vertical spikes indicate 95 percent bootstrap confidence intervals. Gini: black line; Theil index: grey line. Database is EU-SILC (see Section 2.1 for details). Authors' calculations. 
Figure 9b. Inequality in the EU-22 countries without EA-10
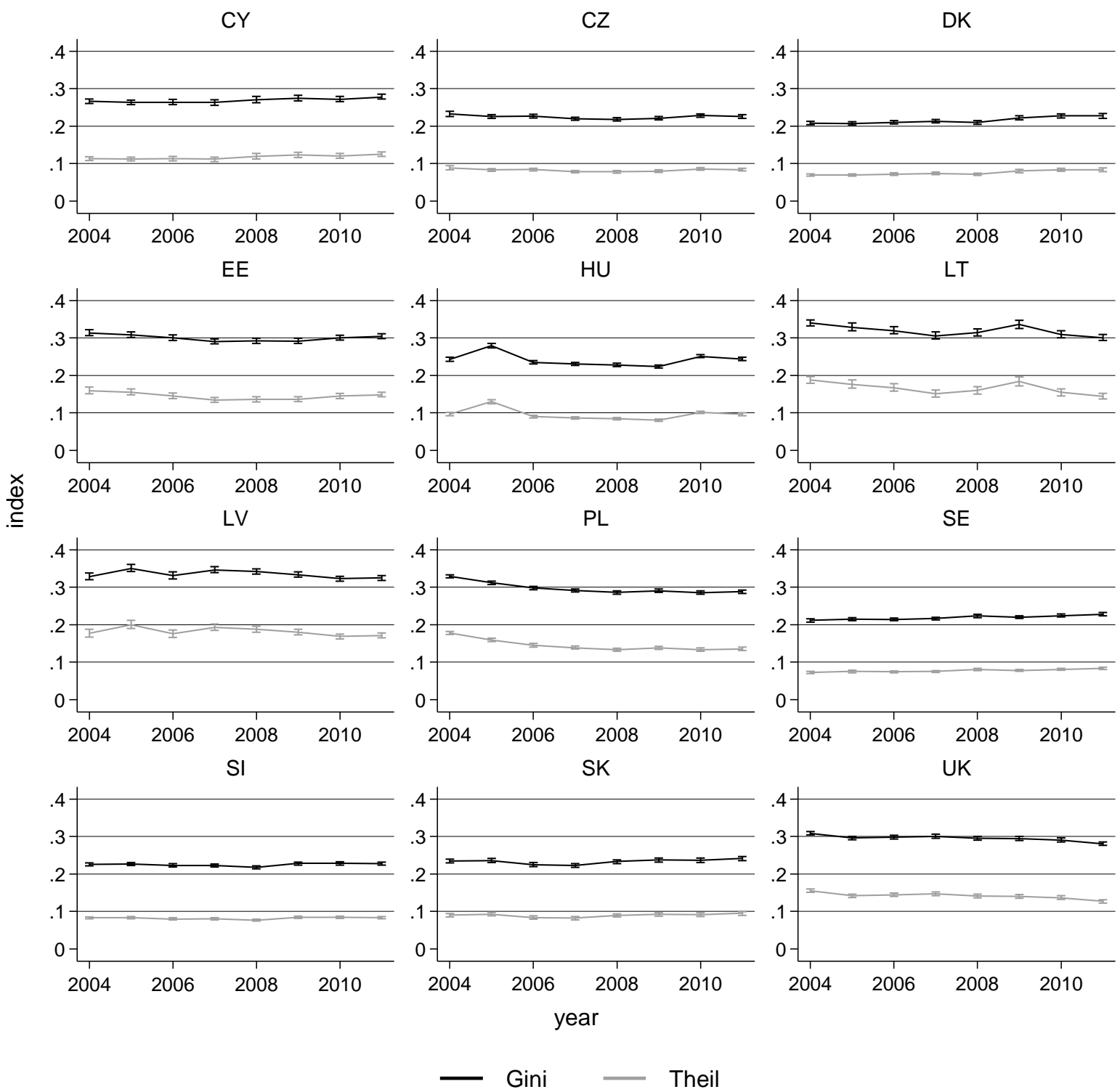

Note. Country-specific inequality indices based on equivalent disposable income. Solid lines connect point estimates. Vertical spikes indicate 95 percent bootstrap confidence intervals. Gini: black line; Theil index: grey line. Database is EU-SILC (see Section 2.1 for details). Authors' calculations. 
Figure 10a. Binational inequality decomposition for EA-10 countries, group G1

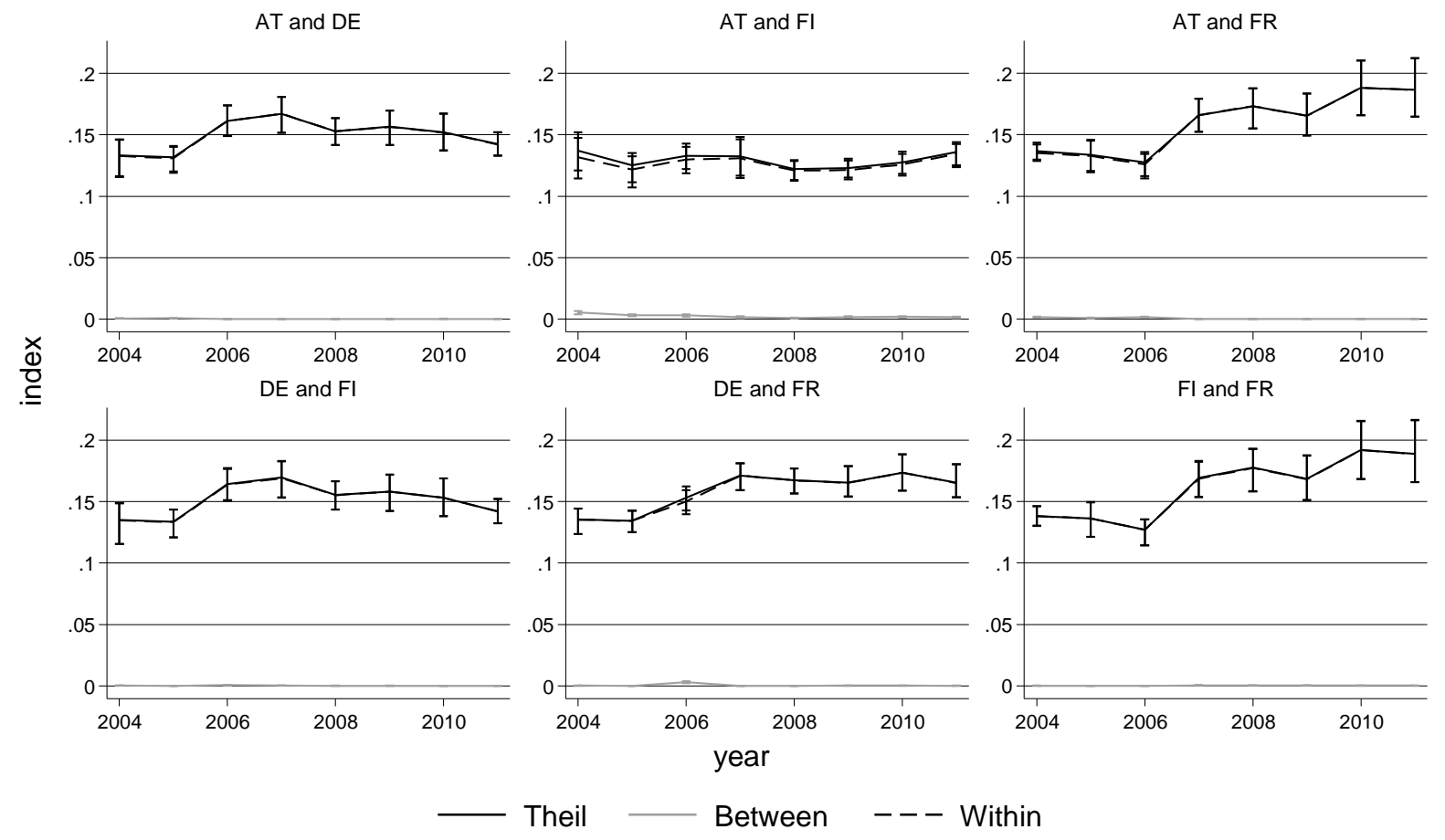

Note. Binational inequality decompositions of Theil index based on equivalent disposable income. Lines connect point estimates. Vertical spikes indicate 95 percent bootstrap confidence intervals. Database is EU-SILC (see Section 2.1 for details). Authors' calculations. 
Figure 10b. Binational inequality decomposition for EA-10 countries, group G2

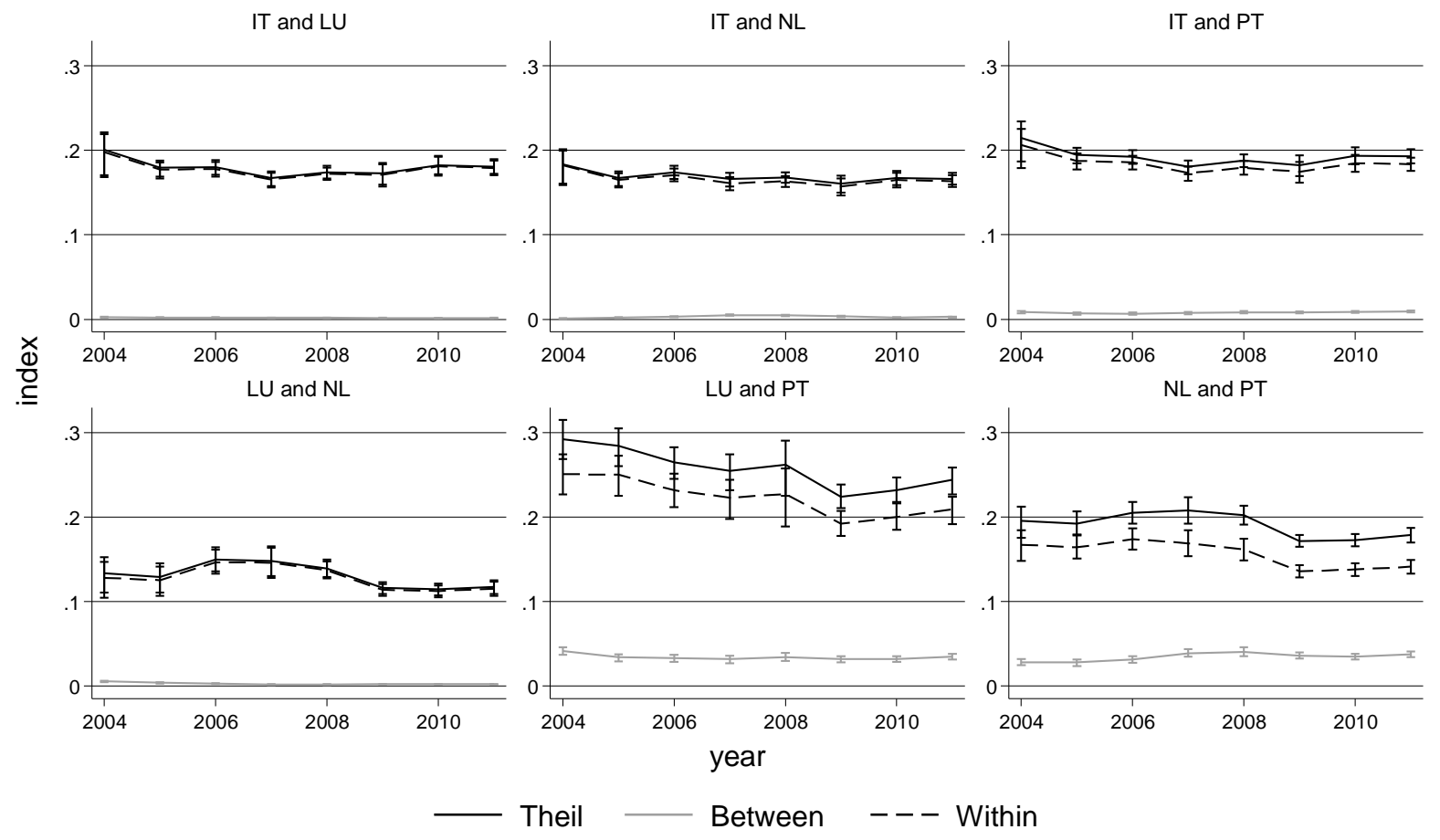

Note. Binational inequality decompositions of Theil index based on equivalent disposable income. Lines connect point estimates. Vertical spikes indicate 95 percent bootstrap confidence intervals. Database is EU-SILC (see Section 2.1 for details). Authors' calculations. 
Figure 10c. Binational inequality decomposition for EA-10 countries, group G3

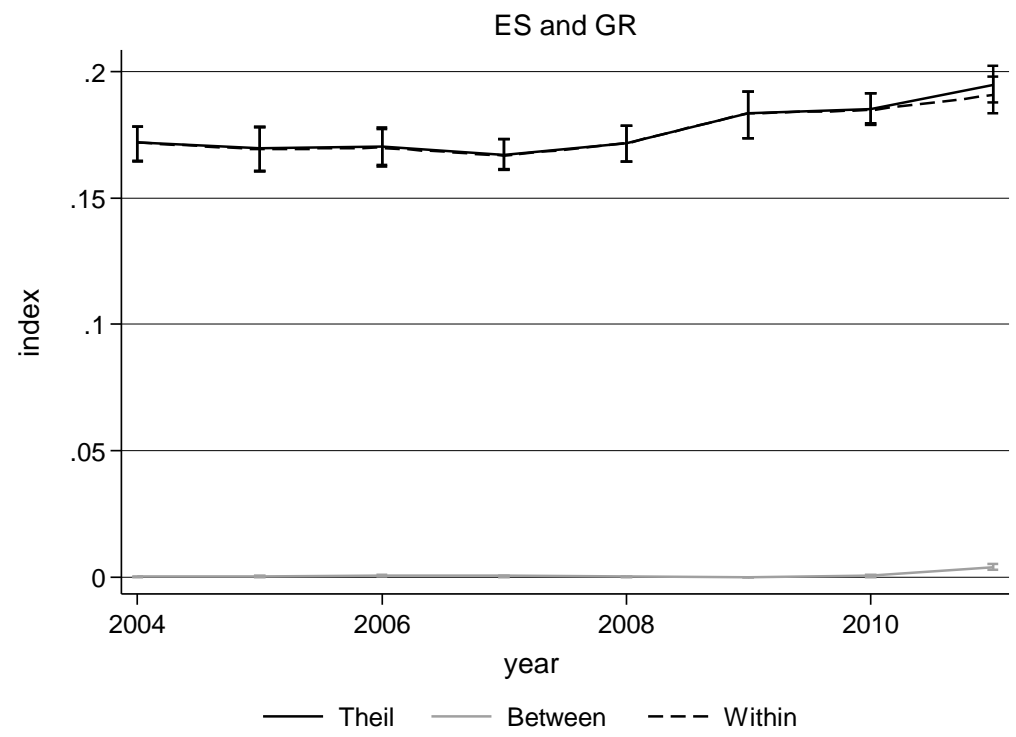

Note. Binational inequality decompositions of Theil index based on equivalent disposable income. Lines connect point estimates. Vertical spikes indicate 95 percent bootstrap confidence intervals. Database is EU-SILC (see Section 2.1 for details). Authors' calculations. 
Figure 11a. Binational inequality decomposition for EA-10 countries, groups $\mathrm{G} 1$ and G2
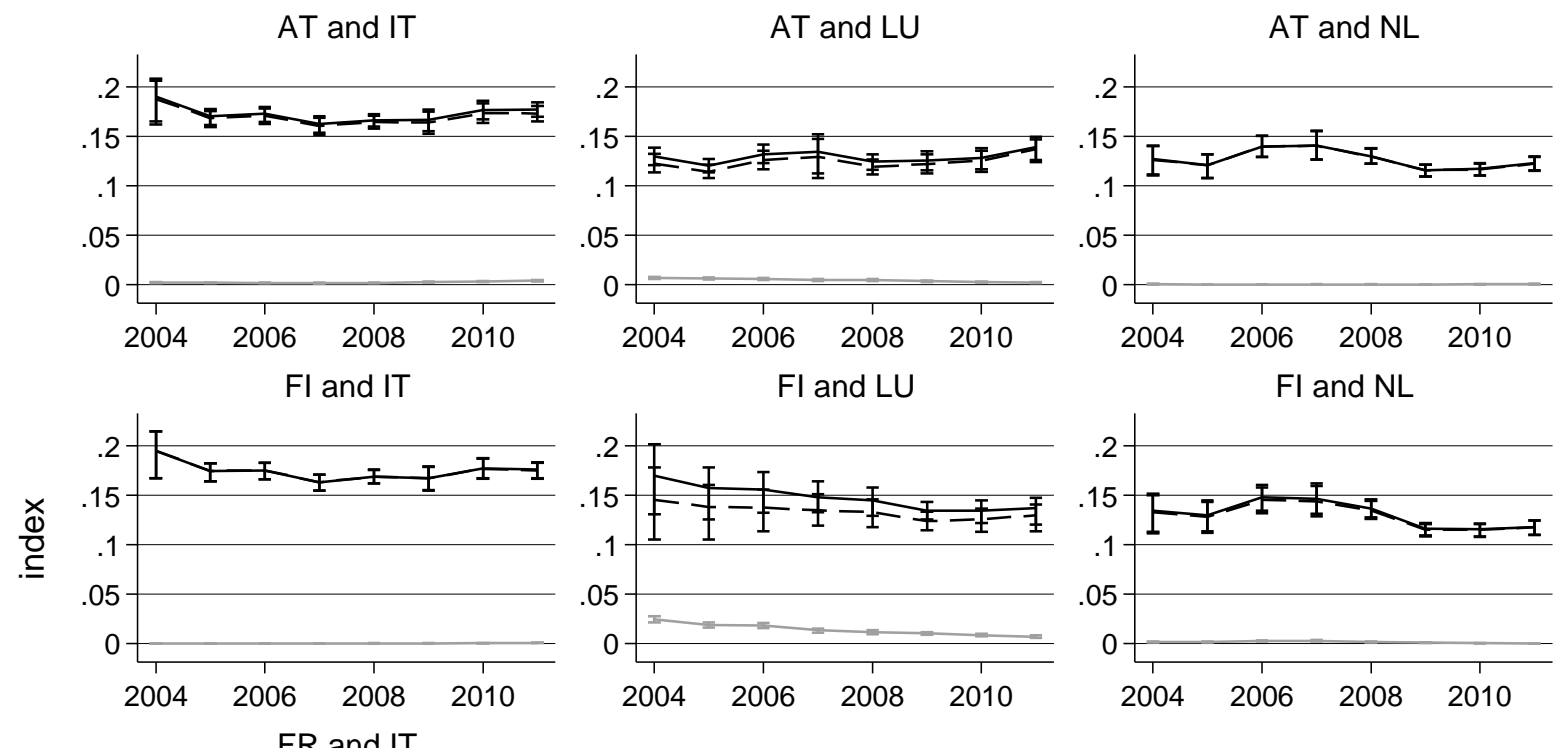

FR and IT

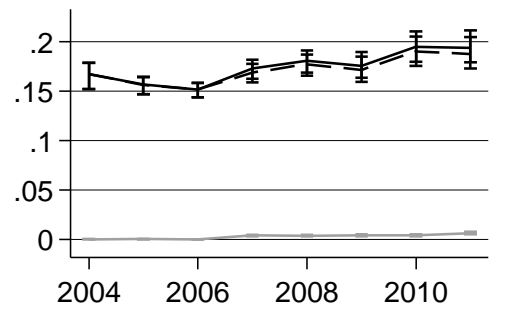

$$
\text { year }
$$

\section{Theil $\quad$ Between $\quad---$ Within}

Note. Binational inequality decompositions of Theil index based on equivalent disposable income. Lines connect point estimates. Vertical spikes indicate 95 percent bootstrap confidence intervals. Database is EU-SILC (see Section 2.1 for details). Authors' calculations. 
Figure 11b. Binational inequality decomposition for EA-10 countries, groups $\mathrm{G} 1$ and G2
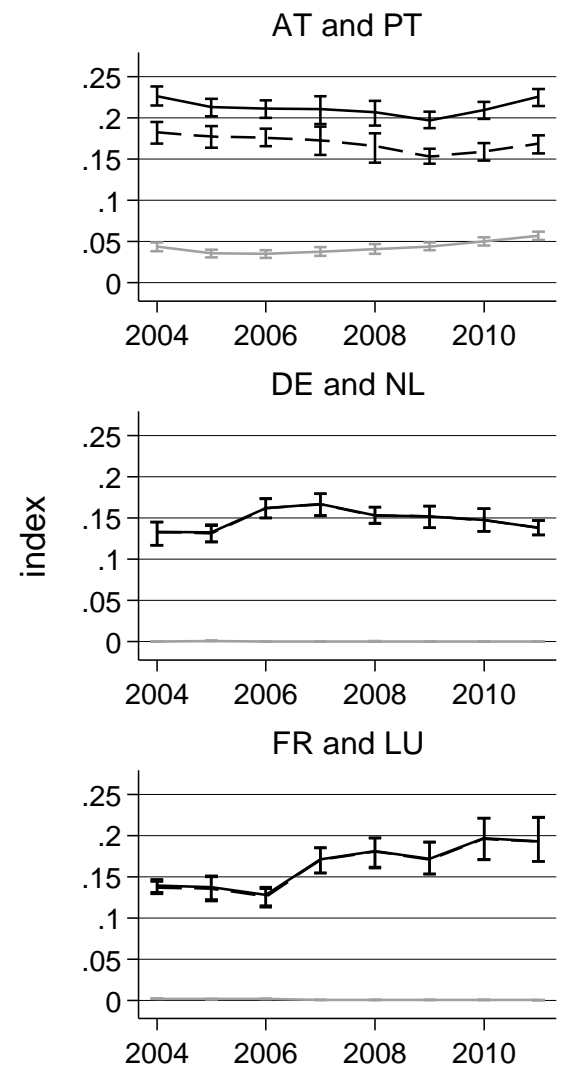

DE and IT

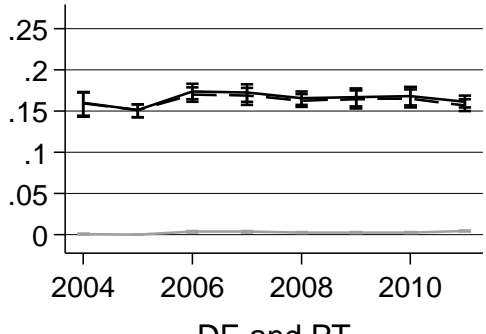

DE and PT

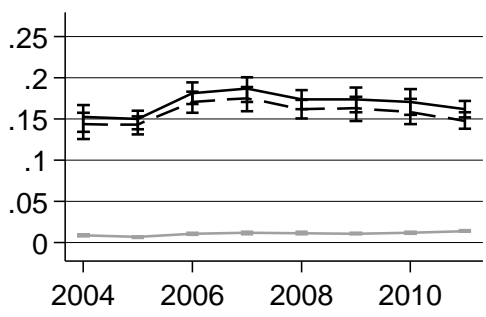

FR and NL

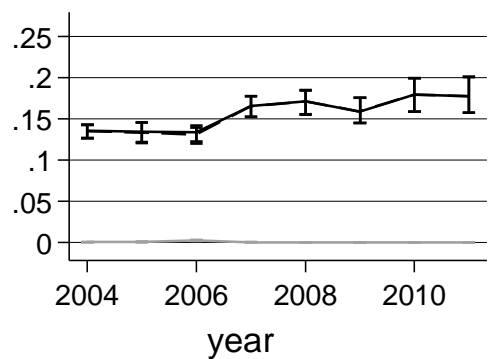

DE and LU
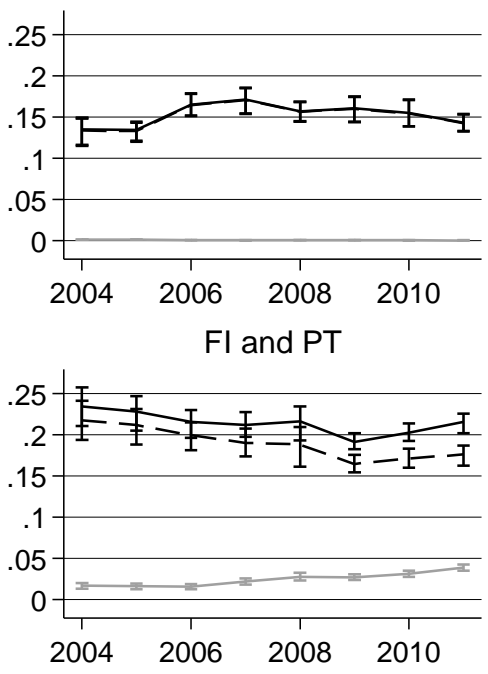

FR and PT

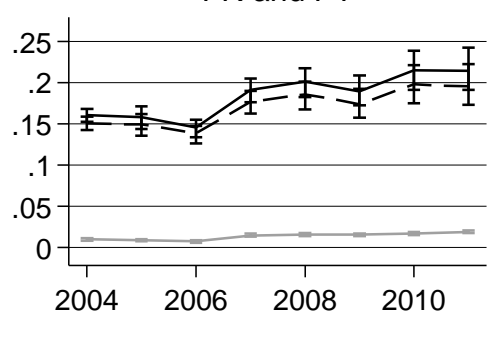

Theil

Between --- Within

Note. Binational inequality decompositions of Theil index based on equivalent disposable income. Lines connect point estimates. Vertical spikes indicate 95 percent bootstrap confidence intervals. Database is EU-SILC (see Section 2.1 for details). Authors' calculations. 
Figure 12a. Binational inequality decomposition for EA-10 countries, groups G1 and G3
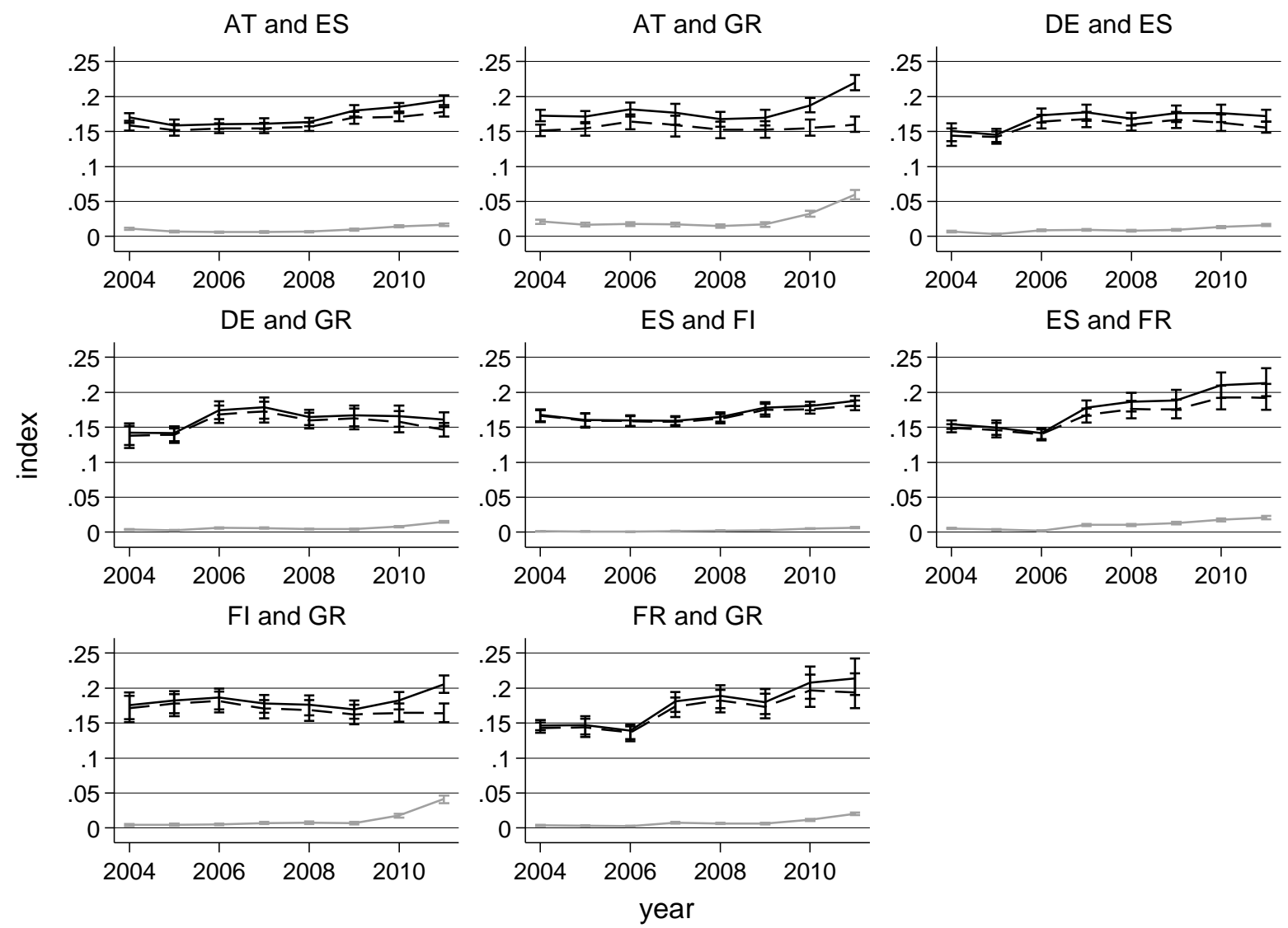

Theil

Between - - - Within

Note. Binational inequality decompositions of Theil index based on equivalent disposable income. Lines connect point estimates. Vertical spikes indicate 95 percent bootstrap confidence intervals. Database is EU-SILC (see Section 2.1 for details). Authors' calculations. 
Figure 12b. Binational inequality decomposition for EA-10 countries, groups $\mathrm{G} 2$ and $\mathrm{G} 3$
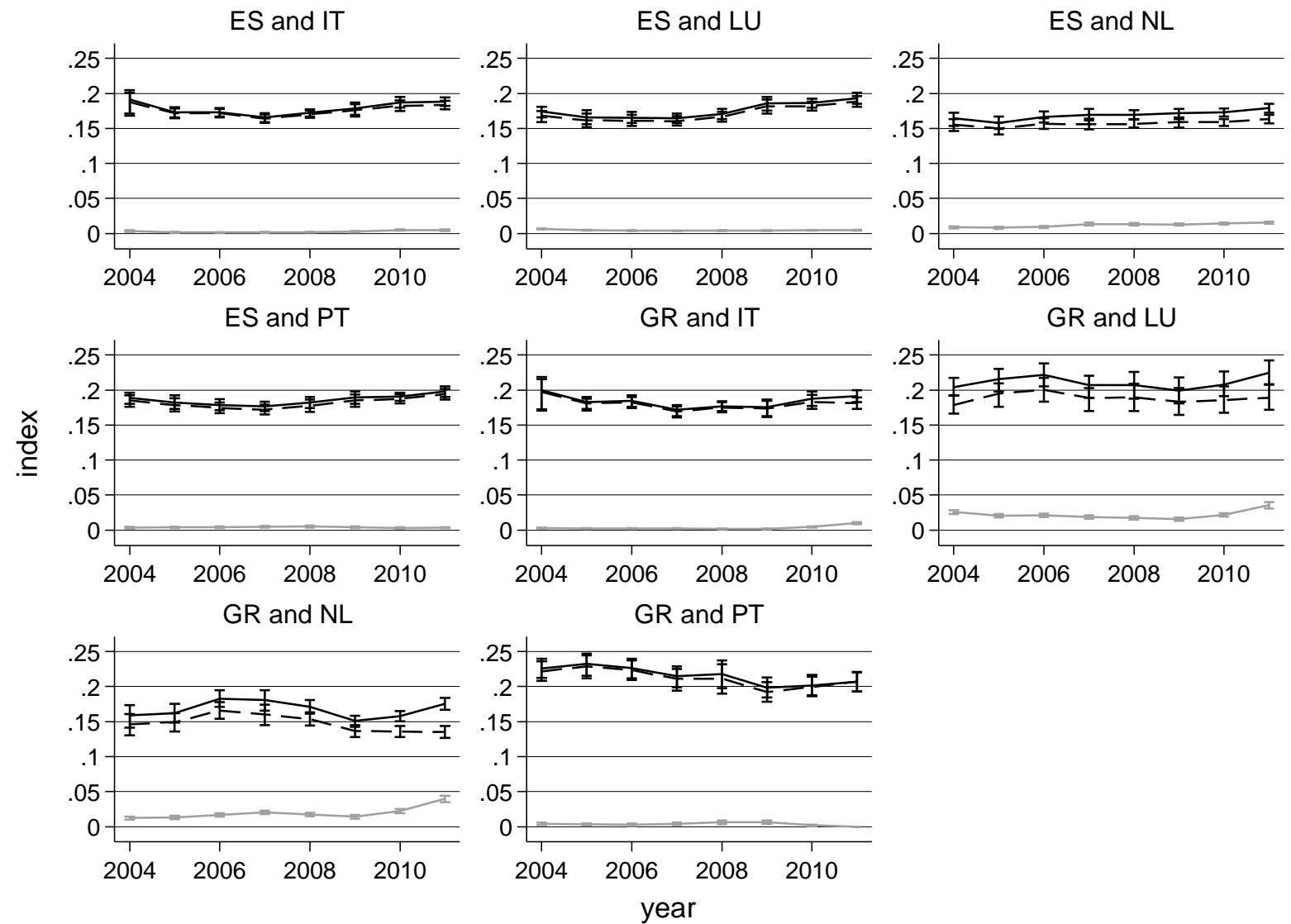

Theil

Between - - - Within

Note. Binational inequality decompositions of Theil index based on equivalent disposable income. Lines connect point estimates. Vertical spikes indicate 95 percent bootstrap confidence intervals. Database is EU-SILC (see Section 2.1 for details). Authors' calculations. 


\section{Appendix}

Table A1. Country-specific population shares in Europe

\begin{tabular}{|c|c|c|c|c|c|c|c|}
\hline \multirow[b]{2}{*}{ Country } & \multirow[b]{2}{*}{$\begin{array}{c}\text { Country } \\
\text { code }\end{array}$} & \multicolumn{3}{|c|}{ EU-22 } & \multicolumn{3}{|c|}{$\mathrm{EA}-10$} \\
\hline & & 2004 & 2011 & $\begin{array}{l}\text { Difference in } \\
\text { percentage } \\
\text { points }\end{array}$ & 2004 & 2011 & $\begin{array}{c}\text { Difference in } \\
\text { percentage } \\
\text { points }\end{array}$ \\
\hline Austria & AT & 1.833 & 1.834 & 0.001 & 2.747 & 2.743 & -0.004 \\
\hline Cyprus & $\mathrm{CY}$ & 0.163 & 0.184 & 0.021 & & & \\
\hline Czech Republic & $\mathrm{CZ}$ & 2.295 & 2.296 & 0.002 & & & \\
\hline Denmark & DK & 1.215 & 1.218 & 0.003 & & & \\
\hline Estonia & $\mathrm{EE}$ & 0.308 & 0.291 & -0.016 & & & \\
\hline Finland & $\mathrm{FI}$ & 1.175 & 1.177 & 0.002 & 1.761 & 1.760 & -0.001 \\
\hline France & FR & 14.022 & 14.229 & 0.208 & 21.012 & 21.278 & 0.266 \\
\hline Germany & DE & 18.578 & 17.902 & -0.675 & 27.840 & 26.771 & -1.069 \\
\hline Greece & GR & 2.485 & 2.436 & -0.049 & 3.723 & 3.643 & -0.081 \\
\hline Hungary & HU & 2.277 & 2.187 & -0.090 & & & \\
\hline Italy & $\mathrm{IT}$ & 12.942 & 13.000 & 0.058 & 19.395 & 19.440 & 0.045 \\
\hline Latvia & LV & 0.512 & 0.454 & -0.058 & & & \\
\hline Lithuania & LT & 0.765 & 0.668 & -0.097 & & & \\
\hline Luxemburg & LU & 0.102 & 0.112 & 0.010 & 0.153 & 0.168 & 0.014 \\
\hline Netherlands & NL & 3.660 & 3.647 & -0.012 & 5.484 & 5.454 & -0.030 \\
\hline Poland & $P L$ & 8.597 & 8.335 & -0.261 & & & \\
\hline Portugal & PT & 2.357 & 2.315 & -0.042 & 3.533 & 3.462 & -0.071 \\
\hline Slovakia & SK & 1.209 & 1.181 & -0.028 & & & \\
\hline Slovenia & SI & 0.449 & 0.449 & 0.000 & & & \\
\hline Spain & ES & 9.577 & 10.219 & 0.642 & 14.352 & 15.282 & 0.930 \\
\hline Sweden & SE & 2.020 & 2.062 & 0.041 & & & \\
\hline United Kingdom & UK & 13.459 & 13.801 & 0.342 & & & \\
\hline Total Population & & $444,256,021$ & $456,649,519$ & $12,393,498$ & $296,453,355$ & $305,376,379$ & $8,923,024$ \\
\hline
\end{tabular}


Table A2. Purchasing-power parities (PPP)

\begin{tabular}{|c|c|c|c|c|c|c|c|c|c|}
\hline Country & $\begin{array}{c}\text { Country } \\
\text { code }\end{array}$ & 2004 & 2005 & 2006 & 2007 & 2008 & 2009 & 2010 & 2011 \\
\hline Austria & AT & 1.034 & 1.027 & 1.021 & 1.027 & 1.052 & 1.079 & 1.051 & 1.057 \\
\hline Cyprus & $\mathrm{CY}$ & 0.908 & 0.892 & 0.890 & 0.880 & 0.878 & 0.898 & 0.887 & 0.887 \\
\hline Czech Republic & $\mathrm{CZ}$ & 17.691 & 17.343 & 17.406 & 17.347 & 19.294 & 19.316 & 18.861 & 18.577 \\
\hline Denmark & DK & 10.398 & 10.477 & 10.335 & 10.241 & 10.427 & 10.648 & 10.458 & 10.626 \\
\hline Estonia & $\mathrm{EE}$ & 0.631 & 0.648 & 0.686 & 0.734 & 0.767 & 0.773 & 0.748 & 0.759 \\
\hline Finland & $\mathrm{FI}$ & 1.240 & 1.238 & 1.229 & 1.197 & 1.208 & 1.240 & 1.217 & 1.222 \\
\hline France & FR & 1.101 & 1.084 & 1.087 & 1.082 & 1.109 & 1.122 & 1.101 & 1.097 \\
\hline Germany & $\mathrm{DE}$ & 1.049 & 1.035 & 1.027 & 1.018 & 1.037 & 1.070 & 1.035 & 1.020 \\
\hline Greece & GR & 0.877 & 0.884 & 0.892 & 0.899 & 0.918 & 0.950 & 0.945 & 0.945 \\
\hline Hungary & HU & 156.240 & 157.414 & 160.451 & 167.875 & 174.768 & 177.237 & 173.455 & 171.917 \\
\hline Italy & IT & 1.051 & 1.049 & 1.043 & 1.026 & 1.026 & 1.048 & 1.012 & 1.029 \\
\hline Latvia & LV & 0.532 & 0.566 & 0.603 & 0.664 & 0.751 & 0.763 & 0.706 & 0.715 \\
\hline Lithuania & LT & 1.850 & 1.897 & 1.982 & 2.074 & 2.280 & 2.312 & 2.195 & 2.227 \\
\hline Luxemburg & LU & 1.032 & 1.118 & 1.115 & 1.149 & 1.173 & 1.215 & 1.223 & 1.233 \\
\hline Netherlands & NL & 1.063 & 1.048 & 1.042 & 1.021 & 1.042 & 1.079 & 1.078 & 1.083 \\
\hline Poland & PL & 2.413 & 2.461 & 2.436 & 2.338 & 2.435 & 2.516 & 2.412 & 2.414 \\
\hline Portugal & PT & 0.875 & 0.852 & 0.851 & 0.858 & 0.880 & 0.892 & 0.874 & 0.878 \\
\hline Slovakia & SK & 0.730 & 0.711 & 0.718 & 0.710 & 0.726 & 0.732 & 0.703 & 0.707 \\
\hline Slovenia & SI & 0.754 & 0.761 & 0.768 & 0.790 & 0.829 & 0.879 & 0.861 & 0.849 \\
\hline Spain & ES & 0.911 & 0.913 & 0.919 & 0.930 & 0.952 & 0.977 & 0.966 & 0.969 \\
\hline Sweden & SE & 11.093 & 11.070 & 10.977 & 10.706 & 10.866 & 11.425 & 11.414 & 11.350 \\
\hline United Kingdom & UK & 0.737 & 0.752 & 0.755 & 0.781 & 0.821 & 0.862 & 0.925 & 0.943 \\
\hline
\end{tabular}

Note. PPP in local currencies, normalized to EU-28 $=1$. Source: Eurostat, Series ESA95. 